\author{
Banco de México \\ Documentos de Investigación
}

Banco de México

Working Papers

$\mathrm{N}^{\circ} 2020-17$

\title{
Crédito Bancario al Sector Privado y Crecimiento Económico en México: Un Análisis con Datos Panel por Entidad Federativa 2005-2018
}

\author{
Leonardo E. Torre Cepeda \\ Banco de México \\ Miguel A. Flores Segovia \\ Banco de México
}

Diciembre 2020

La serie de Documentos de Investigación del Banco de México divulga resultados preliminares de trabajos de investigación económica realizados en el Banco de México con la finalidad de propiciar el intercambio y debate de ideas. El contenido de los Documentos de Investigación, así como las conclusiones que de ellos se derivan, son responsabilidad exclusiva de los autores y no reflejan necesariamente las del Banco de México.

The Working Papers series of Banco de México disseminates preliminary results of economic research conducted at Banco de México in order to promote the exchange and debate of ideas. The views and conclusions presented in the Working Papers are exclusively the responsibility of the authors and do not necessarily reflect those of Banco de México. 


\author{
Documento de Investigación \\ 2020-17 \\ Working Paper \\ 2020-17
}

\title{
Crédito Bancario al Sector Privado y Crecimiento Económico en México: Un Análisis con Datos Panel por Entidad Federativa 2005-2018*
}

\author{
Leonardo E. Torre Cepeda \\ Banco de México
}

\author{
Miguel A. Flores Segovia \\ Banco de México
}

Resumen: El trabajo investiga el efecto del crédito bancario a empresas en el sector privado en los sectores agropecuario, industrial y de servicios sobre el crecimiento del PIB per cápita en México empleando un panel de datos por entidad federativa para el periodo 2005-2018. La estimación controla por variables relacionadas con infraestructura, gasto público, exportaciones, inflación, capital humano, una variable categórica que captura la crisis financiera global de 2008-2009, e introduce un rezago de la variable dependiente para dar cuenta de su posible persistencia. Utilizando el Método Generalizado de Momentos a fin de controlar por posibles efectos endógenos entre las variables, se obtiene que un incremento de $10 \%$ en el crédito bancario como porcentaje del PIB eleva el crecimiento del PIB per cápita entre 0.61 y 0.81 puntos porcentuales. Estos resultados destacan la relevancia de medidas que promueven el sano desarrollo del sistema financiero en México.

Palabras Clave: Crédito Bancario, Crecimiento Económico, Análisis Regional, México

Abstract: The paper investigates the effect of banking credit to private agriculture, industrial and services sectors, on per capita GDP growth in Mexico using panel data at the state level for the period 2005-2018. The estimation controls for variables related to infrastructure, public expenditure, exports, inflation, human capital, a dummy for the 2008-2009 global financial crisis, and introduces a lag of the dependent variable in order to consider its likely persistence. Using the Generalized Method of Moments in order to control for possible endogenous effects among the variables, it is estimated that a $10 \%$ increase in the ratio of banking credit to GDP increases per capita GDP growth at the state level between 0.61 and 0.81 percentage points. These results underline the relevance of policy measures designed to promote a healthy functioning of the financial system in Mexico.

Keywords: Banking Credit, Economic Growth, Regional Analysis, Mexico

JEL Classification: O47, G21, R11, R15

*Los autores agradecen los comentarios de Alejandrina Salcedo, dos dictaminadores anónimos y el apoyo de Eva Edith González. Todos los errores restantes en este documento son responsabilidad exclusiva de los autores.

† Dirección General de Investigación Económica. Correo: leonardo.torre@banxico.org.mx.

‡ Dirección General de Investigación Económica. Correo: mfloress@banxico.org.mx. 


\section{Introducción}

Por mucho tiempo el vínculo entre el crecimiento económico y el otorgamiento de crédito bancario y no bancario al sector privado no financiero ha sido objeto de un intenso escrutinio, tanto en economías desarrolladas, como en economías emergentes. El argumento tradicional en relación con este vínculo es que un incremento en la cantidad de fondos provistos por las instituciones financieras a individuos o empresas, al ser absorbidos por estos agentes para adquirir planta, equipo, bienes duraderos y no duraderos, o bien, financiar gastos recurrentes, impulsa la productividad y el crecimiento económico. Este crecimiento económico alienta, a su vez, el crédito al sector privado no financiero a través de una mayor demanda por productos y servicios financieros. ${ }^{1}$

La evidencia empírica en torno a la relación entre el crédito bancario al sector privado no financiero y el crecimiento económico, sin embargo, dista de ser concluyente. Por ejemplo, estudios apoyados en información a nivel país, o con paneles de países, sugieren que incrementos en el crédito bancario elevan las tasas de crecimiento económico (King y Levine, 1993; Levine y Zervos, 1988; Levine, Loayza y Beck, 2000; Levine 1997 y 2005; Beck, Levine y Loaiza, 2000; Xu, 2000, Beck y Levine, 2004). ${ }^{2}$ Otros trabajos, estos apoyados en información microeconómica, también sustentan la hipótesis de que incrementos en el crédito de la banca comercial al sector privado no financiero son conducentes a mayores tasas de

\footnotetext{
${ }^{1}$ El crédito bancario ha sido utilizado en la literatura como un indicador de desarrollo financiero. Este último, no obstante, es definido por el World Economic Forum (2012) como aquellas políticas, factores e instituciones que resultan en una intermediación eficiente y en mercados financieros efectivos y estables (p.4). En la práctica, sin embargo, dadas las dificultades para medir estas políticas, factores o instituciones, su medición se ha apoyado en el uso de indicadores de profundidad, tamaño, acceso y solidez del sistema financiero, siendo una de ellas el nivel o el crecimiento del crédito bancario al sector privado. Este trabajo se enfoca, sin embargo, en el efecto del crédito bancario al sector privado no financiero sobre el crecimiento económico a nivel de entidad federativa, y no sobre el efecto del desarrollo financiero sobre el crecimiento.

${ }^{2}$ En una síntesis de los principales resultados de estos estudios, Levine (2005) concluye que la contribución del financiamiento al crecimiento económico opera vía cuatro mecanismos principales: (i) Permite a grandes y pequeños inversionistas diversificar riesgos (en su ausencia, los inversionistas preferirían asignar su riqueza a proyectos de bajo riesgo y rendimiento); (ii) facilita el intercambio mediante la reducción de costos de transacción; (iii) mejora la asignación de capital mediante la generación ex-ante de información relacionada con oportunidades de inversión, y (iv) eleva la disposición de los inversionistas a financiar nuevos proyectos gracias a la combinación de monitoreo ex-post y provisión de gobernanza corporativa. La revisión de Levine (2005) incluye casi 300 referencias, en tanto que revisiones más recientes sobre el tema (Beck et al., 2014; Pasali, 2013) consideran más de 100 referencias correspondientes al periodo 2005-2013. Véase también Bucci y Marsiglio (2019).
} 
crecimiento económico (Demirgüç-Kunt y Maksimovic, 1995; Rajan y Zingales, 1998; Guiso et al., 2004; Serres et al., 2006; Hassan y Klapper, 2006; Beck et al., 2008; Musso y Schiavo 2008; Kendall, 2009; Bardhan y Sharma, 2017). ${ }^{3}$

No obstante, también se encuentra literatura que reporta un efecto negativo del financiamiento sobre el crecimiento económico a nivel macroeconómico (De Gregorio y Guidotti, 1995; Hassan et al., 2011); o bien, que la relación puede ser en forma de " $U$ invertida", lo que implica que si bien un incremento en el crédito bancario puede ejercer un efecto positivo sobre la tasa de crecimiento económico, dicho efecto perdura solo hasta cierto punto (Deidda y Fattouh, 2002; Law y Singh, 2014; Aizenmann et al., 2015; Sahay et al., 2015; Bucci y Marsiglio, 2019). ${ }^{4,5}$ Adicionalmente, se tiene a quienes proponen que los sistemas financieros son irrelevantes para explicar el crecimiento económico agregado. ${ }^{6}$

\footnotetext{
${ }^{3}$ De acuerdo con Giovannini et al. (2013), el surgimiento de este enfoque microeconómico responde a que los trabajos empíricos que estudian la relación entre el financiamiento y el crecimiento económico desde una perspectiva macroeconómica con datos panel por país, que son los que predominan en la literatura, enfrentan diversos problemas econométricos, entre los que destacan la omisión de variables relevantes, sesgo de selección, problemas con el tamaño de muestra, multicolinealidad, además de que revelan ser muy sensibles a las técnicas econométricas utilizadas.

${ }^{4}$ De Gregorio y Guidotti (1995) proponen que expansiones excesivas del crédito bancario y no bancario pueden generar fuertes repuntes en la actividad económica y burbujas en los precios de los activos, combinación que eventualmente se traduce en crisis financieras que provocan largos periodos de estancamiento, o de bajo crecimiento económico. La volatilidad macroeconómica resultante de estas crisis propicia, en consecuencia, el desperdicio de recursos escasos, desincentiva el ahorro y promueve la especulación, lo que a su vez se traduce en niveles sub-óptimos de inversión productiva, una mala asignación de los recursos disponibles y, finalmente, en menores tasas de crecimiento. Estos autores estiman regresiones con datos panel de 12 países latinoamericanos para el periodo 1950-1985 y reportan la presencia de una fuerte relación negativa entre el grado de intermediación financiera y el crecimiento económico durante los 1970s y 1980s, resultado que atribuyen a las crisis financieras que enfrentaron algunas de estas economías en el periodo revisado. A su vez, Hassan et al. (2011) emplean un panel de 168 países para el periodo 1960-2007 y reportan que si bien en países de ingreso bajo y medio se observa una relación positiva entre el nivel de desarrollo del crédito doméstico y el crecimiento económico, en países de ingreso elevado la relación es negativa. Por su parte, Rajan y Zingales (1998) muestran que las industrias que requieren más financiamiento crecen a tasas más bajas en países con mercados de capital menos desarrollados, resultado que atribuyen a la presencia de restricciones financieras, estas últimas asociadas probablemente a la falta de colateral por parte de los demandantes de crédito.

${ }^{5}$ Otros autores también han reportado que la contribución del crédito al crecimiento económico muestra diferencias entre países y niveles de ingreso (Barajas et al., 2013; Nili y Rastad, 2007; Demetriades y Hussein, 1996; Arestis et al., 2002); que el efecto del crédito bancario sobre el crecimiento económico tiende a ser mayor en economías donde sus sistemas financieros son de tamaño medio (Rioja y Valev, 2004); o bien, que la relación entre estas variables no es constante e incluso se ha debilitado con el tiempo (Rousseau y Wachtel, 2011).

${ }^{6}$ Fama (1980) muestra, por ejemplo, que en un sistema bancario competitivo, donde los bancos tienen las mismas oportunidades de acceso a los mercados de capitales, un cambio en la decisión de otorgar un préstamo por parte de una institución de manera individual, no tiene efectos sobre la actividad real en un marco de equilibrio general.
} 
En el caso de México, los trabajos en torno a la relación entre el crédito bancario al sector privado no financiero y el crecimiento económico tampoco arrojan un consenso. Por ejemplo, Arestis y Demetriadis (1999) revisan información anual para el periodo 1951-1992 y concluyen, a partir de una ecuación de cointegración, que el crédito bancario total exhibe una relación de largo plazo estable con el crecimiento del PIB real per cápita, y que "dicha relación es bidireccional, lo que sugiere que el sistema bancario en México jugó un papel positivo en el proceso de desarrollo del país" en el periodo analizado [p.53]. Por su parte, Venegas et al. $(2009,2014)$ analizan la reacción del PIB ante cambios en un "índice de desarrollo financiero" estimado mediante componentes principales, que incluyó al crédito bancario al sector privado, activos de los bancos comerciales y activos de otras instituciones financieras. Utilizando información anual para los periodos 1960-2003 y 1969-2011, y apoyados también en un análisis de cointegración, los autores reportan que su medida de desarrollo financiero ejerce un efecto relativamente modesto sobre las tasas de crecimiento del PIB real en el largo plazo, además de que no identifican una relación de corto plazo entre las variables de interés. Por su parte, Rodríguez y López (2009) revisan el periodo 1961-2003 y reportan que el financiamiento, medido como el cociente de M4 a PIB nominal, no solo ejerce un efecto positivo sobre el crecimiento económico, sino que la relación es bidireccional. A su vez, De la Cruz y Alcántara (2011) revisan el efecto del crédito bancario total al sector privado (medido como el otorgado a los sectores primario, secundario y terciario) sobre el crecimiento económico a nivel agregado. Utilizando información mensual para el periodo enero/1995-noviembre/2010, los autores reportan que el crédito bancario total causa al crecimiento del IGAE, lo que les lleva a plantear que, “de manera general, la expansión del crédito genera crecimiento, algo que se encuentra en concordancia con la teoría que postula al sistema financiero como factor de desarrollo económico" [p.31]. No obstante, también mencionan que la relación positiva y de largo plazo que detectan entre el crecimiento económico con el crecimiento del financiamiento bancario "tiene su verdadero vínculo con los recursos encaminados al consumo" [p.31], no con los sectores productivos (primario y secundario). De allí que sugieran que la interacción entre el sector real y el sistema bancario sea limitada. En resumen, en el caso de México los trabajos utilizan información agregada, 
distintos periodos de tiempo, distintos indicadores de financiamiento y llegan a conclusiones diferentes.

A diferencia de la literatura existente sobre el tema en México que, como se menciona arriba, se apoya en información a nivel agregado y con datos previos al año 2012, este trabajo analiza el efecto que sobre la tasa de crecimiento del PIB per cápita ejerce un componente del financiamiento bancario total al sector privado no bancario: el crédito bancario a las empresas privadas no financieras de los sectores agropecuario, industrial y de servicios. ${ }^{7}$ En particular, se somete a prueba la hipótesis de que incrementos en el financiamiento bancario a las empresas privadas no financieras, al inducir una mayor movilización de recursos a proyectos productivos, se traducen en mayores tasas de crecimiento económico per cápita (Levine et al., 2000).

A diferencia de los trabajos existentes sobre el tema en México, la estimación utiliza un panel de datos a nivel estatal para el periodo 2005-2018, donde la heterogeneidad no observada de las entidades federativas (como políticas económicas locales, rasgos geográficos, demográficos y culturales) se controla mediante la introducción de efectos fijos de entidad federativa. ${ }^{8}$ Este análisis, por tanto, se espera revele más información sobre la eficiencia del sistema bancario y capture de mejor forma las relaciones contractuales entre los bancos y sus clientes, algo que no es posible capturar con datos a nivel país en los estudios internacionales. El análisis controla por la inclusión de factores que en la literatura económica se reconoce ejercen un efecto sobre el crecimiento del PIB per cápita, como capital humano, gasto público, inflación, orientación exportadora, e infraestructura. La estimación incluye también una variable dicotómica que toma el valor " 1 " para 2008-2009, y "0" para el resto del periodo, a fin de incorporar el efecto que sobre la economía mexicana pudo haber ejercido la crisis económica global. Dada la posible persistencia en la tasa de crecimiento del PIB per

\footnotetext{
${ }^{7}$ Debe mencionarse que el análisis no consideró el crédito bancario al sector público, a la vivienda y al consumo, dado que no se tiene un el desglose por entidad federativa de estos componentes. Por la misma razón, tampoco se incluyó el componente del crédito no bancario al sector privado. De tenerse este desglose, podría construirse una variable de crédito al sector privado no financiero total por entidad federativa, haciendo que esta se acercara más a la utilizada, por ejemplo, en Levine et al. (2000) en su trabajo a nivel de países.

${ }^{8}$ El periodo de estudio 2005-2018 se definió en función de la disponibilidad de información para la variable "crédito bancario otorgado por la banca múltiple, según residencia del acreditado, a las empresas de los sectores agropecuario, industrial y de servicios a nivel de entidad federativa", la cual está disponible a partir del 2003.
} 
cápita estatal, se introduce también como determinante un rezago de la misma. Esta especificación, no obstante, genera el problema de que el rezago de la variable dependiente y el término de error estén correlacionados, a lo que se agrega una posible endogeneidad entre el crecimiento del PIB per cápita y el crédito bancario a las empresas privadas no financieras, así como entre los otros regresores. En esta situación, el estimador de Mínimos Cuadrados Ordinarios es sesgado e inconsistente. Por lo anterior, se propone estimar el modelo mediante el Método Generalizado de Momentos. ${ }^{9}$ Este método, que emplea rezagos y diferencias rezagadas de las probables variables endógenas, restablece la consistencia de las estimaciones, controla por posibles casos de endogeneidad y, además, "resulta eficiente dentro de la clase de estimadores de variables instrumentales" (Nucci y Pozzolo, 2010).

Las estimaciones sugieren que incrementos en el nivel del crédito bancario a las empresas privadas no financieras de los sectores agropecuario, industrial y de servicios, elevan la tasa de crecimiento del PIB per cápita estatal, resultado congruente con el énfasis otorgado en México -y a nivel internacional- en torno a la necesidad de impulsar medidas de política que estimulen el sano desarrollo del sistema financiero al interior de un país. ${ }^{10}$

\footnotetext{
${ }^{9}$ Vea Holtz-Eakin et al. (1988); Arellano y Bond (1991); Arellano y Bover (1995) y Blundell y Bond (1998).

${ }^{10}$ En este sentido, el 8 de enero de 2019 las autoridades financieras en México anunciaron la puesta en marcha del Programa de Impulso al Sector Financiero. De acuerdo con las autoridades, el programa busca profundizar tanto el sector bancario, como el mercado de valores, proveer de medios de pago más eficientes a la población, y hacer más eficiente la labor de captación del ahorro y su canalización a la inversión productiva, elementos necesarios "para impulsar un crecimiento económico más dinámico, incluyente y equitativo. Para ello, el programa se apoya en ocho ejes: i) impulsar la inclusión financiera mediante el desarrollo de una banca digital; ii) fortalecer y mejorar las condiciones en las que los trabajadores acceden a los créditos de nómina; iii) permitir que los mexicanos entre 15 y 17 años puedan abrir cuentas bancarias a su nombre y sin contar con un tutor; iv) impulsar el mercado de bonos al actualizar el sistema que permite el préstamo de valores; v) fortalecer el régimen de las Afores y el ahorro voluntario; vi) homologar el tratamiento tributario para los tenedores de bonos nacionales y extranjeros; vii) impulsar el mercado de capitales mediante un mecanismo que permita incubar empresas que después salgan a la bolsa; y viii) otorgar mayor flexibilidad a intermediarios financieros en sus operaciones. Véase Comunicado de Prensa No. 003-2019 de la SHCP, publicado el 8 de enero de 2019. Estas medidas pueden interpretarse como complementarias a la "Reforma Financiera Integral" que entró en vigor en enero de 2014, que modificó 31 leyes federales e introdujo una nueva (la Ley Federal para Regular las Agrupaciones Financieras). Dicha reforma se centró en cuatro áreas: fomentar la competencia en todo el sector financiero, fortalecer el marco normativo, el mandato y la capacidad operativa de la banca de desarrollo de ampliar el acceso al crédito; ampliar el crédito de instituciones financieras privadas permitiéndoles a las autoridades financieras una evaluación más sistemática del crédito bancario comercial para canalizarlo de manera más eficiente; y asegurar que el sistema financiero sea sólido y estable. Para una revisión de la evolución del sistema bancario mexicano en el periodo 1990-2014, vea Hernández y Villagómez (2013), y Nava y Dorantes (2016). Para una revisión histórica del desarrollo de la banca en México, vea Turrent (2007).
} 
El trabajo está organizado como sigue. La sección 2 revisa algunos aspectos del comportamiento reciente del crédito bancario a las empresas de los sectores agropecuario, industrial y servicios en México a nivel regional y por entidad federativa. La sección 3 describe las variables a utilizar en el periodo bajo estudio y presenta el modelo econométrico; la sección 4 muestra los resultados de la estimación; la sección 5 concluye.

\section{Crédito Bancario al Sector Privado No Financiero y Crecimiento del PIB en México en el Periodo 2005-2018}

Este trabajo utiliza información correspondiente al PIB por entidad federativa proveniente del INEGI, con el fin de calcular la tasa de crecimiento del PIB per cápita por entidad federativa como indicador de crecimiento económico. Para la variable de crédito bancario se utiliza el crédito bancario otorgado por la banca múltiple, según residencia del acreditado, a las empresas de los sectores agropecuario, industrial y de servicios a nivel de entidad federativa, publicado por el Sistema de Información Económica del Banco de México, como fracción del PIB estatal. ${ }^{11}$ La medida excluye, dado que no se cuenta con el desglose por entidad federativa correspondiente, el crédito bancario al sector público, a la vivienda y al consumo.

Una revisión al agregado del crédito de la banca comercial a las empresas privadas no financieras de los sectores agropecuario, industrial y de servicios como porcentaje del PIB de las 32 entidades federativas revela una tendencia ascendente para esta variable durante el periodo 2005-2018, lo que se traduce en que a lo largo del mismo el crédito más que se duplique (Gráfica 1). ${ }^{12}$ Cuando se compara la información entre entidades federativas se pueden apreciar otras características de su comportamiento. Por ejemplo, la Gráfica 2 ordena las entidades de acuerdo con su PIB per cápita de 2018, donde destaca la diferencia entre el nivel del crédito bancario a los sectores agropecuario, industrial y de servicios en la entidad

\footnotetext{
${ }^{11}$ La banca comercial, o banca múltiple, agrupa instituciones de crédito privadas residentes en el país, que incluyen bancos nacionales, filiales de bancos extranjeros establecidos en México, así como sus agencias en el extranjero.

${ }^{12}$ Se debe mencionar que aún y cuando la variable de crédito bancario por entidad federativa utilizada en este trabajo excluye el otorgado al sector público, a la vivienda y al consumo (estas dos últimas solo están disponibles a nivel nacional), la suma de estos 32 valores estatales tiene una correlación de $96 \%$ con la variable de crédito bancario disponible a nivel nacional para el periodo 2005-2018. Véase Apéndice 2.
} 
con mayor PIB per cápita (Ciudad de México: 31.1\%) y el reportado en la entidad con menor

PIB per cápita (Guerrero: 1.2\%).

\section{Gráfica 1}

Crédito de la Banca Comercial a las Empresas Privadas No Financieras por Entidad Federativa 2005-2018*

Saldo vigente, \% PIB

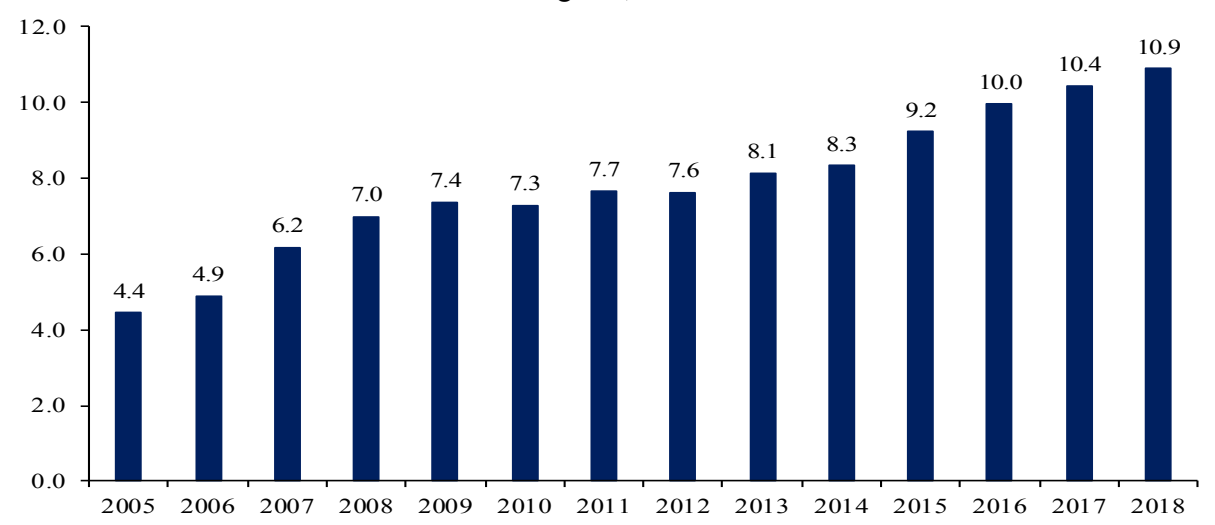

*/ Nota: La variable de crédito de la banca comercial a las empresas privadas no financieras incluye el otorgado a aquellas de los sectores agropecuario, industrial y de servicios; excluye el crédito a la vivienda, al consumo y al sector público. Fuente: Elaboración propia con información del Banco de México e INEGI.

\section{Gráfica 2}

Crédito de la Banca Comercial a las Empresas Privadas No Financieras por Entidad Federativa 2018* Saldo vigente, $\%$ PIB

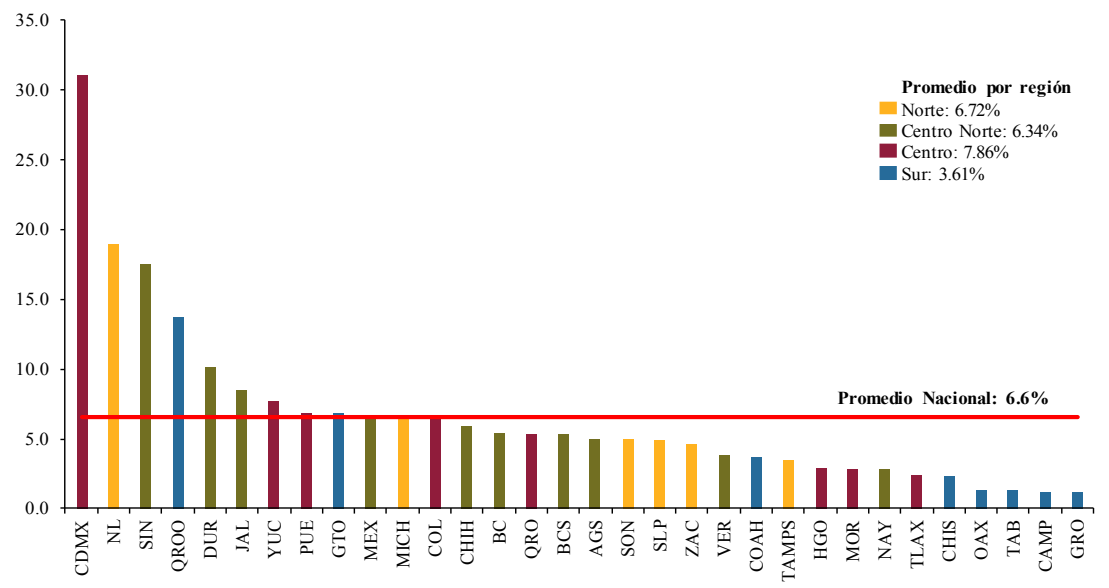

*/ Nota: La variable de crédito de la banca comercial a las empresas privadas no financieras incluye el otorgado a aquellas de los sectores agropecuario, industrial y servicios; excluye crédito a la vivienda, al consumo y al sector público. Los promedios por región del crédito bancario al sector privado no financiero son aritméticos.

Fuente: Elaboración propia con información del Banco de México e INEGI. 
Siguiendo con la Gráfica 2, se observa que las ocho entidades con el PIB per cápita más alto registran un saldo promedio como porcentaje del PIB 7.6 veces mayor al observado en las ocho entidades con el PIB per cápita más bajo (14.3\% vs. 1.9\%, respectivamente). Asimismo, al agrupar los datos de crédito por región (norte, centro norte, centro y sur) con información a 2018, se observa que las entidades de la región centro reportan un saldo promedio 2.2 veces mayor que el reportado en la sur ( $7.86 \%$ vs. $3.61 \%$, respectivamente). ${ }^{13}$ Es decir, entre entidades y entre regiones, existen diferencias notorias en sus niveles de crédito otorgado al sector privado.

La Gráfica 3 presenta, a su vez, una primera aproximación a un posible vínculo positivo entre la actividad económica y el crédito bancario al sector privado a nivel de entidad federativa. En este caso, la información arroja un coeficiente de correlación de Spearman positivo (0.65) y estadísticamente significativo entre el crecimiento promedio para el periodo 2005-2018 del PIB per cápita estatal y el saldo del crédito de la banca comercial como porcentaje del PIB estatal. ${ }^{14}$ Se aprecia una correlación positiva y estadísticamente significativa entre el crecimiento promedio de la actividad económica estatal en el periodo 2005-2018 y el promedio del crédito bancario a las empresas no privadas no financieras como porcentaje del PIB estatal en el mismo periodo.

\footnotetext{
${ }^{13}$ Se emplea la regionalización propuesta por el Banco de México (2020). Norte: Baja California, Chihuahua, Nuevo León, Sonora y Tamaulipas; Centro-Norte: Aguascalientes, Baja California Sur, Colima, Durango, Jalisco, Michoacán, Nayarit, San Luis Potosí, Sinaloa y Zacatecas; Centro: Ciudad de México, Estado de México, Guanajuato, Hidalgo, Morelos, Puebla, Querétaro y Tlaxcala; Sur: Campeche, Chiapas, Guerrero, Oaxaca, Quintana Roo, Tabasco, Veracruz y Yucatán.

${ }^{14}$ El nivel del crédito bancario al sector privado no financiero total en México es bajo en relación con estándares internacionales: apenas una cuarta parte del registrado en economías emergentes, y una sexta parte del promedio de las economías avanzadas. Al respecto, Herman y Klemm (2017) estiman que la brecha de largo plazo entre el crédito bancario total observado y el esperado en México es cercana al $40 \%$ del PIB, y proponen que crisis bancarias recurrentes, un amplio sector informal y un sistema legal ineficiente se encuentran entre los principales factores detrás de dicha brecha.
} 
Gráfica 3

Crecimiento Económico y Saldo del Crédito de la Banca Comercial

a las Empresas Privadas No Financieras

Promedios 2005-2018 por Entidad Federativa

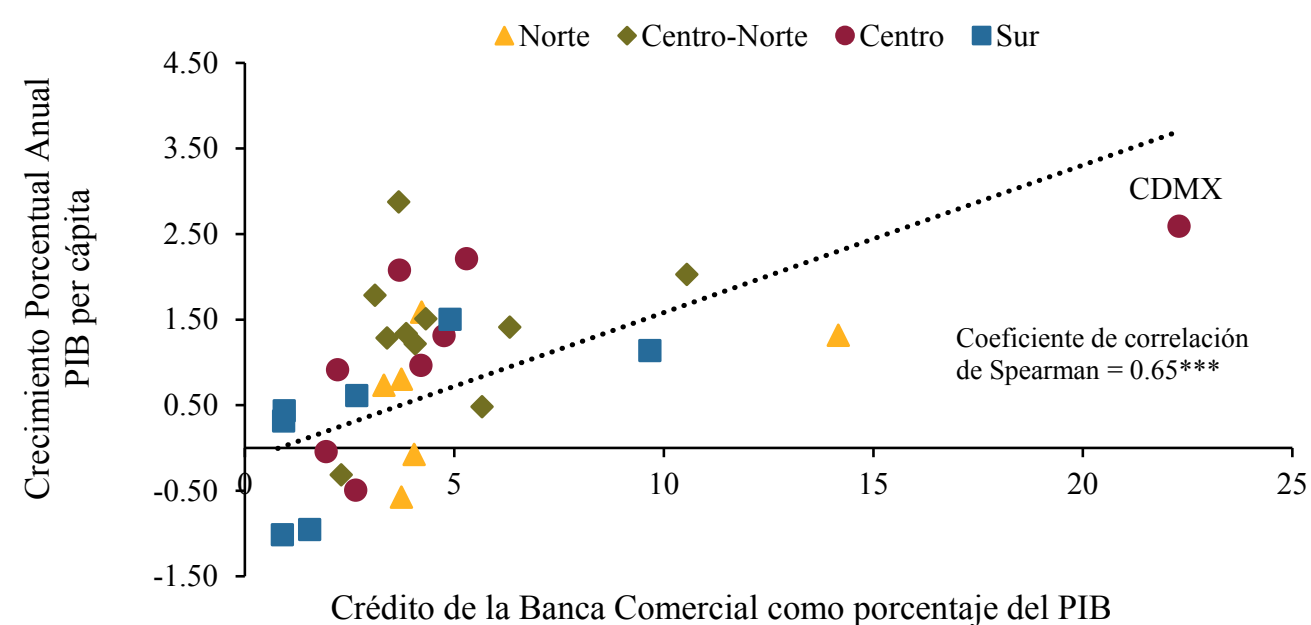

Nota: *** denota significancia estadística al $1 \%$. Si se excluye a la Ciudad de México, el coeficiente de correlación de Spearman baja a 0.62 , pero continúa siendo estadísticamente significativo al $1 \%$. Los puntos muestran el valor promedio de las variables en el periodo 2005-2018 por entidad federativa; el color representa la región.

Fuente: Estimaciones propias con información del Banco de México e INEGI.

No obstante, a fin de determinar si el crédito bancario a las empresas privadas no financieras de los sectores agropecuario, industrial y de servicios ejerce un efecto positivo sobre el crecimiento económico en el periodo 2005-2018, requiere de una estimación econométrica. La siguiente sección presenta el modelo econométrico a estimar y la sección 4 presenta los resultados.

\section{Modelo Econométrico}

Dado que se tiene un panel de datos anuales por entidad federativa para el periodo 20052018, el efecto del crédito de la banca comercial a las empresas no financieras de los sectores agropecuario, industrial y servicios como porcentaje del PIB estatal, sobre el crecimiento económico del PIB per cápita estatal se lleva a cabo siguiendo a Levine et al. (2000). Estos autores proponen estimar un modelo dinámico en datos panel especificado como sigue:

$$
y_{i, t}-y_{i, t-1}=(\gamma-1) y_{i, t-1}+\beta^{\prime} \boldsymbol{X}_{i, t}+\alpha_{i}+\varepsilon_{i, t}
$$


donde, para efectos de este trabajo, $y_{i, t}$ es el logaritmo del PIB real per cápita estatal; $y_{i, t-1}$ es el logaritmo del PIB real per cápita estatal rezagado un periodo; $\boldsymbol{X}$ representa un vector de variables explicativas; $\alpha_{i}$ es el efecto fijo relacionado con las entidades federativas, que controla por la heterogeneidad no observada de las entidades que no cambia en el tiempo; $\varepsilon$ representa el término del error, y los subíndices $i$ y $t$ representan la entidad federativa y el año, respectivamente. La ecuación (1) se puede reescribir como sigue:

$$
y_{i, t}=\gamma y_{i, t-1}+\beta^{\prime} \boldsymbol{X}_{i, t}+\alpha_{i}+\varepsilon_{i, t}
$$

Al obtener las primeras diferencias de (2) para eliminar los efectos fijos asociados con las entidades federativas, se llega a la siguiente expresión:

$$
y_{i, t}-y_{i, t-1}=\gamma\left(y_{i, t-1}-y_{i, t-2}\right)+\beta^{\prime}\left(\boldsymbol{X}_{i, t}-\boldsymbol{X}_{i, t-1}\right)+\left(\varepsilon_{i, t}-\varepsilon_{i, t-1}\right)
$$

En (3), el crecimiento del PIB real per cápita estatal aparece como variable dependiente y se encuentra expresada en función de su rezago -controlando así por un posible efecto de persistencia- y de los cambios en las variables explicativas contenidas en el vector $\boldsymbol{X}$.

Dado que en la ecuación (3) aparece el rezago de la variable dependiente como variable explicativa, el estimador de Mínimos Cuadrados Ordinarios (OLS) resulta sesgado e inconsistente debido a que dicho rezago se encuentra correlacionado con el término de error (Nickell, 1981). Por ello, el modelo (3) se estimará con el Método Generalizado de Momentos en Diferencias propuesto por Arellano y Bond (1991) y Holtz-Eakin et al. (1988). Este método de estimación controla por: (1) la dependencia intertemporal de la variable dependiente y su rezago, y (2) la posible endogeneidad asociada con la inclusión de ciertas variables explicativas, usando para esto sus rezagos como instrumentos (Baltagi, 2013). No obstante, como señalan Levine et al. (2000), existen también algunas limitantes conceptuales y estadísticas con el estimador de Método Generalizado de Momentos en Diferencias. Con respecto a las primeras, sería deseable tomar en cuenta la heterogeneidad de las entidades federativas al analizar la relación entre el crédito bancario y el crecimiento del PIB per cápita estatal, misma que es eliminada en el estimador en diferencias. En torno a las limitaciones estadísticas, Alonso-Borrego y Arellano (1999) y Blundell y Bond (1998) muestran que cuando las variables explicativas son persistentes en el tiempo, sus rezagos son instrumentos 
débiles para los modelos a estimar en diferencias. Por tanto, con el fin de reducir el sesgo e imprecisión potenciales asociados al estimador en diferencias, en este trabajo se estima el efecto del crédito bancario al sector privado no financiero a nivel estatal sobre el crecimiento del PIB per capital estatal utilizando también el Método Generalizado de Momentos en Sistemas propuesto por Arellano y Bover (1995) y Blundell y Bond (1997), el cual combina en un sistema las regresiones en diferencias y en niveles. ${ }^{15,16}$

El conjunto de variables explicativas en $\boldsymbol{X}_{i, t}$ se describe a continuación. En primer lugar, incluye la variable explicativa de interés de este trabajo: crédito bancario a las empresas privadas no financieras de los sectores agropecuario, industrial y de servicios, como porcentaje del PIB por entidad federativa (CREDITO). También incluye como controles otras variables que en la literatura se consideran determinantes del crecimiento económico. Entre ellas, Capital Humano, medido por la proporción de la población ocupada con nivel de instrucción media y superior por entidad federativa; Infraestructura, capturada con la longitud de la red de carreteras expresada en kilómetros por entidad federativa como medida de infraestructura; Gasto Público, capturado con el gasto público como proporción del PIB por entidad federativa; además de la tasa de inflación anual estatal (Inflación); las exportaciones como porcentaje del PIB por entidad federativa como medida de exposición al comercio internacional (Exportaciones); y una variable dicotómica que toma el valor "1" para 2008-2009, y “0” para otros años, a fin de incorporar el efecto sobre la economía mexicana de la crisis económica global (Crisis). ${ }^{17}$ En el modelo todas las variables están expresadas en logaritmos, con excepción de la variable dicotómica, los efectos fijos por entidad federativa y la tasa de inflación.

\footnotetext{
${ }^{15} \mathrm{El}$ uso de rezagos como instrumentos puede darse a través de niveles $t-n$ de las variables endógenas, o de las diferencias de estos valores $x_{(t-n)}-x_{(t-(n-1))}$.

${ }^{16}$ El Método Generalizado de Momentos en Diferencias se utiliza regularmente cuando se tienen paneles con un $t$ (periodo de tiempo) largo. Con paneles cortos, esto es, con un $t$ reducido, y por tanto con pocos instrumentos, se utiliza el Método Generalizado de Momentos en Sistemas; vea Porras y Rosales (2014).

${ }^{17}$ El gasto público como porcentaje del PIB considera los egresos de los gobiernos estatales y municipales por servicios personales, materiales y suministros, a servicios generales, transferencias, asignaciones, subsidios y otras ayudas, bienes muebles, inmuebles e intangibles, inversión pública, inversiones financieras y otras provisiones, recursos reasignados a municipios, obligaciones de deuda pública y disponibilidad final.
} 


\section{Resultados}

Antes de proceder con las estimaciones, se debe tener presente que aun con datos panel es posible que surjan algunos problemas propios de series de tiempo. Por ejemplo, existe la posibilidad de que la variable dependiente no sea estacionaria, lo que, en caso de ser cierto, llevaría a reconsiderar la especificación propuesta en la sección 3. Para atender este punto, el Cuadro 1 presenta los resultados de diversas pruebas de raíces unitarias en datos panel para el crecimiento del PIB real per cápita estatal. ${ }^{18}$ En específico, se realizaron las pruebas propuestas por Levin, Lin, and Chu (2002); Im, Pesaran y Shin (2003), además de las pruebas Dickey-Fuller Aumentada y Phillips-Perron (Choi, 2001). En todas ellas, la hipótesis nula consiste en la existencia de una raíz unitaria. El Cuadro 1 muestra que todas las pruebas rechazan que el crecimiento del PIB real per cápita estatal contenga una raíz unitaria, implicando que puede procederse con la estimación mediante las especificaciones y métodos sugeridos en la sección previa.

\section{Cuadro 1}

Resultado de Pruebas de Raíces Unitarias en Panel de Datos para Crecimiento del PIB real per cápita por Entidad Federativa 2005-2018 $\mathrm{N}=32, \mathrm{~T}=14$

Hipótesis Nula: La serie presenta una raíz unitaria.

\begin{tabular}{lrc}
\hline Prueba Estadística & Estadístico & $p$-value \\
\hline Levin, Lin, and Chu (2002); estadístico-t & $-9.12^{* * *}$ & $<0.001$ \\
Im, Pesaran, and Shin (2003); estadístico- $W$ & $-6.27^{* * *}$ & $<0.001$ \\
ADF-Fisher $\chi^{2}$ & $195.06^{* * *}$ & $<0.001$ \\
PP-Fisher Chi-Square $\chi^{2}$ & $350.78^{* * *}$ & $<0.001$ \\
\hline
\end{tabular}

Nota: Los símbolos ***,** y* denotan significancia del $1 \%, 5 \%$ y $10 \%$, respectivamente.

Como se especificó anteriormente, el Método Generalizado de Momentos, tanto en Diferencias como en Sistemas, permite controlar por la posible endogeneidad asociada con la inclusión de ciertas variables explicativas, como podría ser la misma variable CRÉDITO. En este caso, CRÉDITO podría ser modelada como un determinante endógeno de la tasa

\footnotetext{
${ }^{18}$ Normalmente se sugiere probar la hipótesis de si una variable es o no estacionaria durante el periodo analizado cuando el número de periodos $(\mathrm{T})$ es mayor que el número de unidades $(\mathrm{N})$; en cambio, si $\mathrm{T}<\mathrm{N}$, no es necesario realizarla. En este trabajo $\mathrm{T}<\mathrm{N}$, dado que se tienen $\mathrm{T}=14$ años y $\mathrm{N}=32$ entidades federativas. Aun así, se realizaron las pruebas para datos panel propuestas por Levin, Lin, and Chu (2002); Im, Pesaran y Shin (2003), además de las pruebas Dickey-Fuller Aumentada y Phillips-Perron (Choi, 2001) para el crecimiento del PIB real per cápita estatal.
} 
anual de crecimiento del PIB real per cápita estatal dada la posible causalidad bidireccional entre estas variables. Con el fin de identificar la posible relación causal entre las variables explicativas incluidas en el análisis con el crecimiento del PIB real per cápita estatal, se utilizan modelos de vectores autorregresivos para datos panel, de donde es posible estimar la prueba de causalidad de Granger en panel de datos propuesta por Abrigo y Love (2016). Los resultados del Cuadro 2 indican la presencia de una causalidad bidireccional de CRÉDITO y Exportaciones con el crecimiento del PIB per cápita estatal.

\section{Cuadro 2}

Prueba de Causalidad Granger en Panel de Datos

\begin{tabular}{|c|c|c|c|c|c|}
\hline \multicolumn{3}{|c|}{ Relación Causal } & \multirow{2}{*}{$\frac{\text { Rezago }}{1}$} & \multirow{2}{*}{$\frac{\chi^{2}}{2.446}$} & \multirow{2}{*}{$\frac{p \text {-value }}{0.118}$} \\
\hline Crec. PIB per cápita & $\not \Rightarrow$ & CRÉDITO & & & \\
\hline CRÉDITO & $\not$ & Crec. PIB per cápita & 1 & 2.925 & $0.087^{*}$ \\
\hline Crec. PIB per cápita & $\not$ & CRÉDITO & 2 & 4.99 & $0.082 *$ \\
\hline CRÉDITO & $\not$ & Crec. PIB per cápita & 2 & 3.44 & 0.179 \\
\hline Crec. PIB per cápita & $\not$ & Infraestructura & 1 & 0.043 & 0.836 \\
\hline Infraestructura & $\not \Rightarrow$ & Crec. PIB per cápita & 1 & 2.297 & 0.130 \\
\hline Crec. PIB per cápita & $\not$ & Infraestructura & 2 & 2.379 & 0.304 \\
\hline Infraestructura & $\not \Rightarrow$ & Crec. PIB per cápita & 2 & 1.298 & 0.523 \\
\hline Crec. PIB per cápita & $\not \Rightarrow$ & Gasto Público & 1 & 0.385 & 0.535 \\
\hline Gasto Público & $\not$ & Crec. PIB per cápita & 1 & 1.789 & 0.180 \\
\hline Crec. PIB per cápita & $\not$ & Gasto Público & 2 & 3.074 & 0.215 \\
\hline Gasto Público & $\not \Rightarrow$ & Crec. PIB per cápita & 2 & 1.144 & 0.564 \\
\hline Crec. PIB per cápita & $\not$ & Exportaciones & 1 & 0.829 & 0.363 \\
\hline Exportaciones & $\not$ & Crec. PIB per cápita & 1 & 0.0769 & 0.380 \\
\hline Crec. PIB per cápita & $\not \Rightarrow$ & Exportaciones & 2 & 15.292 & $0.000 * * *$ \\
\hline Exportaciones & $\not$ & Crec. PIB per cápita & 2 & 16.898 & $0.000^{* * *}$ \\
\hline Crec. PIB per cápita & $\not \Rightarrow$ & Inflación & 1 & 4.021 & $0.045 * *$ \\
\hline Inflación & $\not$ & Crec. PIB per cápita & 1 & 0.362 & 0.547 \\
\hline Crec. PIB per cápita & $\not \Rightarrow$ & Inflación & 2 & 5.243 & $0.073^{*}$ \\
\hline Inflación & $\not$ & Crec. PIB per cápita & 2 & 2.973 & 0.226 \\
\hline Crec. PIB per cápita & $\not \Rightarrow$ & Capital Humano & 1 & 0.091 & 0.763 \\
\hline Capital Humano & $\nRightarrow$ & Crec. PIB per cápita & 1 & 0.158 & 0.691 \\
\hline Crec. PIB per cápita & $\not$ & Capital Humano & 2 & 3.107 & 0.212 \\
\hline Capital Humano & $\not$ & Crec. PIB per cápita & 2 & 2.241 & 0.326 \\
\hline
\end{tabular}

Nota: El símbolo $\nRightarrow$ denota “no causalidad." Los símbolos $* * *, * *$ y $*$ denotan significancia al $1 \%, 5 \%$ y $10 \%$, respectivamente.

Fuente: Estimaciones propias con base en información del Banco de México e INEGI.

En particular, se rechaza la hipótesis nula de no causalidad de Granger del crecimiento del PIB real per cápita estatal hacia CRÉDITO cuando se considera un rezago de estas variables; en tanto que la hipótesis de no causalidad de Granger se rechaza en la dirección 
del CRÉDITO hacia crecimiento del PIB real per cápita estatal cuando se consideran dos rezagos de ambas variables. Asimismo, la prueba de causalidad de Granger rechaza la hipótesis nula de no causalidad de Granger con dirección del crecimiento del PIB real per cápita estatal hacia las Exportaciones, y viceversa, cuando se consideran dos rezagos de ambas variables.

Derivado de los resultados anteriores, en la estimación se considera la endogeneidad de estas dos variables y se contrastan las estimaciones obtenidas mediante los modelos dinámicos del Método Generalizado de Momentos en Diferencias y en Sistemas. Los coeficientes estimados del modelo se presentan en el Cuadro 3, donde el panel a) refiere a la estimación con el Método Generalizado de Momentos en Diferencias, y el panel b) a la realizada con el Método Generalizado de Momentos en Sistemas. ${ }^{19}$ Las columnas (1) y (4) muestran las estimaciones incluyendo a $y_{i, t-1}$, que corresponde al efecto dinámico asociado al PIB real per cápita, y a la variable CRÉDITO, excluyendo al resto de las variables de control. Las columnas (2) y (5) muestran la estimación excluyendo solamente la variable dicotómica Crisis, mientras que (3) y (6) muestran las estimaciones incluyendo todas las variables explicativas. Si bien en todas las especificaciones se corrobora la no presencia de autocorrelación serial de orden dos, tal como lo muestra la prueba de Arellano-Bond (2), no es posible rechazar la prueba de sobre-identificación de Hansen en los modelos dinámicos de las especificaciones (2), (5), y (6). ${ }^{20,21}$ En estas especificaciones se hace notar que el

\footnotetext{
${ }^{19}$ Los modelos de Método Generalizado de Momentos en Diferencias o en Sistemas pueden ser estimados mediante dos variantes: Un paso (One Step) o Dos pasos (Two step). El primero utiliza la matriz de pesos homocedástica para la estimación; el segundo utiliza la matriz de pesos heterocedástica, siendo este mecanismo asintóticamente más eficiente. Los resultados descritos reportan la variante de estimación en Dos pasos.

${ }^{20}$ Las pruebas AR(1) y AR(2) que aparecen en el Cuadro 3 son pruebas de correlación serial de primer y segundo orden, respectivamente. Es de esperar una AR(1) significativa, es decir, presencia de correlación serial de primer orden debido a la primera diferencia de las variables. No obstante, para justificar la estimación de modelos dinámicos, considerando los rezagos de las variables explicativas como instrumentos ya sea en diferencias o niveles, se debe mostrar evidencia de no existencia de autocorrelación de segundo orden; es decir, la prueba AR(2) debe resultar no significativa. Los resultados obtenidos en el Cuadro 3 corroboran la presencia de autocorrelación de primer orden en todas las especificaciones, y la no presencia de autocorrelación de segundo orden en todas las especificaciones, con excepción de la especificación 3.

${ }^{21}$ Dada la generación de instrumentos en diferencias o niveles, es posible que surjan más instrumentos de los necesarios, produciéndose una "sobre-identificación" del modelo. Roodman (2009) propone las pruebas de contraste de Sargan y Hansen con el fin de comprobar la validez de los instrumentos utilizados. La prueba de Sargan es adecuada cuando la estimación se ha realizado con la matriz de pesos homocedástica, o sea, en Un paso; mientras que la Prueba de Hansen se emplea con la matriz de pesos heterocedástica, es decir, cuando se
} 
coeficiente estimado de la variable CRÉDITO mantiene tanto su signo positivo esperado, como su significancia estadística. No obstante, las especificaciones (5) y (6) corresponden a la estimación mediante el Método Generalizado de Momentos en Sistemas, siendo esta última la que arroja un mayor número de variables de control con significancia estadística, por lo cual es la preferida para la discusión que a continuación se presenta.

Cuadro 3

Crecimiento del PIB per cápita y Crédito de la Banca Comercial por Entidad Federativa Estimación del Modelo de Panel Dinámico Variable Dependiente: Crecimiento del PIB real per cápita estatal

\begin{tabular}{|c|c|c|c|c|c|c|}
\hline \multirow[b]{2}{*}{ Variables Explicativas: } & \multicolumn{3}{|c|}{ a) GMM en Diferencias } & \multicolumn{3}{|c|}{ b) GMM en Sistemas } \\
\hline & (1) & (2) & (3) & (4) & (5) & (6) \\
\hline CRÉDITO & $\begin{array}{l}-0.008 \\
(0.007)\end{array}$ & $\begin{array}{l}0.050^{* * *} \\
(0.018)\end{array}$ & $\begin{array}{l}0.016 \\
(0.017)\end{array}$ & $\begin{array}{l}0.029 * * * \\
(0.009)\end{array}$ & $\begin{array}{l}0.066^{* *} \\
(0.027)\end{array}$ & $\begin{array}{l}0.081^{* *} \\
(0.031)\end{array}$ \\
\hline$y_{t-1}$ & $\begin{array}{l}0.083^{*} \\
(0.049)\end{array}$ & $\begin{array}{l}-0.073 \\
(0.107)\end{array}$ & $\begin{array}{l}-0.081 \\
(0.072)\end{array}$ & $\begin{array}{l}-0.004^{* * *} \\
(0.001)\end{array}$ & $\begin{array}{l}0.068 \\
(0.044)\end{array}$ & $\begin{array}{l}0.070^{* *} \\
(0.030)\end{array}$ \\
\hline Exportaciones & & $\begin{array}{l}-0.003 \\
(0.036)\end{array}$ & $\begin{array}{l}0.029 \\
(0.027)\end{array}$ & & $\begin{array}{l}0.067 \\
(0.040)\end{array}$ & $\begin{array}{l}0.067^{*} \\
(0.036)\end{array}$ \\
\hline Inflación & & $\begin{array}{l}-0.145^{* * * *} \\
(0.028)\end{array}$ & $\begin{array}{l}-0.054 \\
(0.038)\end{array}$ & & $\begin{array}{l}-0.149 * * * \\
(0.023)\end{array}$ & $\begin{array}{l}-0.212^{* * *} \\
(0.075)\end{array}$ \\
\hline Gasto Público & & $\begin{array}{l}-0.028^{* *} \\
(0.013)\end{array}$ & $\begin{array}{l}-0.021 * * \\
(0.009)\end{array}$ & & $\begin{array}{l}-0.041^{*} \\
(0.020)\end{array}$ & $\begin{array}{l}-0.042^{* *} \\
(0.018)\end{array}$ \\
\hline Infraestructura & & $\begin{array}{l}-0.258^{* *} \\
(0.100)\end{array}$ & $\begin{array}{l}-0.203 * * * \\
(0.070)\end{array}$ & & $\begin{array}{l}-0.015 \\
(0.061)\end{array}$ & $\begin{array}{l}-0.013 \\
(0.041)\end{array}$ \\
\hline Capital Humano & & $\begin{array}{l}0.026 \\
(0.033)\end{array}$ & $\begin{array}{l}0.019 \\
(0.022)\end{array}$ & & $\begin{array}{l}0.172 * * \\
(0.073)\end{array}$ & $\begin{array}{l}0.167 * * \\
(0.069)\end{array}$ \\
\hline Dummy de Crisis & & & $\begin{array}{l}-0.034^{* * *} \\
(0.012)\end{array}$ & & & $\begin{array}{l}0.031 \\
(0.038)\end{array}$ \\
\hline Observaciones & 384 & 352 & 352 & 416 & 384 & 384 \\
\hline Entidades & 32 & 32 & 32 & 32 & 32 & 32 \\
\hline Número de Instrumentos & 7 & 17 & 17 & 7 & 17 & 17 \\
\hline Prueba AR(1) & 0.000 & 0.000 & 0.000 & 0.000 & 0.000 & 0.000 \\
\hline Prueba AR(2) & 0.934 & 0.368 & 0.0295 & 0.382 & 0.322 & 0.772 \\
\hline Prueba de Hansen ( $p$-value) & 0.000 & 0.102 & 0.001 & 0.004 & 0.237 & 0.241 \\
\hline
\end{tabular}

Nota: Errores estándar robustos a heteroscedasticidad entre paréntesis. GMM hace referencia a "Método Generalizado de Momentos." En el Método Generalizado de Momentos en Diferencias el efecto dinámico se captura mediante el rezago de la tasa de crecimiento del PIB real per cápita; en tanto que en Sistemas, este se captura mediante el rezago del logaritmo del PIB real per cápita. Dado que se usa la variante en Dos pasos, se utiliza la corrección de errores estándar para muestras finitas propuesta por Windmeijer (2005). Los símbolos $* * *, * * \mathrm{y} *$ denotan significancia al 1\%, 5\% y 10\%, respectivamente.

Fuente: Estimaciones propias con información del Banco de México e INEGI.

utiliza el mecanismo de estimación en Dos pasos. Davidson y MacKinnon (2004, p.365) se refieren a esta prueba de sobre-identificación como la prueba Hansen-Sargan. 
De acuerdo con esta especificación, el coeficiente estimado de la variable CRÉDITO de 0.081, implica que el componente exógeno de un incremento de $10 \%$ en el financiamiento bancario a las empresas privadas no financieras como porcentaje del PIB, eleva la tasa de crecimiento económico per cápita estatal en 0.81 puntos porcentuales. ${ }^{22}$ Los resultados implican, por ejemplo, que si el crédito bancario al sector privado no bancario de la región sur se incrementara al nivel reportado por la región con el mayor nivel de financiamiento, en este caso la centro, la tasa anual de crecimiento de su PIB real per cápita se incrementaría en 5.6 puntos porcentuales. $^{23}$

Otro ejercicio contrafactual de interés consiste en analizar el efecto sobre la tasa de crecimiento del PIB real per cápita de una entidad federativa cuando esta pasa de un cuartil inferior a uno superior dentro de la distribución de CRÉDITO. Así, por ejemplo, si Guerrero, que se encuentra ubicado en el último cuartil, elevara su nivel de CRÉDITO al nivel registrado en el estado de Morelos, esta última entidad ubicada en el tercer cuartil, entonces la tasa de crecimiento del PIB real per cápita de Guerrero se incrementaría 7.1 puntos porcentuales. ${ }^{24}$ Ambos ejercicios resaltan, por tanto, las oportunidades para promover, a través del impulso al desarrollo financiero regional del país, el crecimiento económico de las

\footnotetext{
${ }^{22}$ Los diferentes estudios empíricos revisados en este trabajo sugieren que la magnitud del coeficiente estimado de la variable $C R E ́ D I T O$ varía en función de, por ejemplo, cómo se mida esta última, del periodo de estudio, del método de estimación utilizado, la selección de variables explicativas, el número de instrumentos en los modelos de panel dinámicos, el nivel geográfico utilizado, entre otros factores. Por ejemplo, Levine (2005), en su estudio para una muestra de 77 paises en el periodo 1960-1995, emplea promedios de cinco años para las variables utilizadas en sus diferentes especificaciones, y reporta que el coeficiente de CRËDITO varía en un intervalo de 0.0176 a 0.0240 (pp. 902-904). A su vez, Bardhan y Sharma (2017), en su trabajo a nivel estatal para la India en el periodo 1981-2012, utilizan promedios de tres años de las variables y reportan que el coeficiente de CRÉDITO varía en sus diferentes especificaciones en un intervalo de 0.0166 a 0.0383 (pp. 635-636). En estos dos trabajos -y al margen de que Levine (2005) utiliza datos a nivel país y Bardhan y Sharma (2017) emplean datos a nivel estatal- la estrategia de utilizar promedios de cinco y tres años de las variables, respectivamente, podría estar suavizando los valores de las series utilizadas, lo que a su vez podría explicar, parcialmente, por qué los coeficientes estimados de la variable CRÉDITO tienden a ubicarse por debajo de los valores estimados en el presente trabajo, que utilizan directamente información anual.

${ }^{23}$ Dado que el crédito bancario se expresa en logaritmo natural, el efecto se calcula al multiplicar el coeficiente de CRÉDITO en la columna (6), por el cambio en el logaritmo de CRÉDITO. El promedio de CRÉDITO en la región sur para el año 2018 es $4.06 \%$, por lo que alcanzar el cociente de crédito de la región centro equivaldría a elevarlo a $8.06 \%$. Con esto, se estima: $[\ln (8.06)-\ln (4.06)]^{*} 0.081 * 100=0.686 * 0.081 * 100=5.6$ puntos porcentuales.

${ }^{24}$ El nivel de crédito bancario a las empresas no financieras en el estado de Guerrero para el 2018 es $1.15 \%$ del PIB, por lo que alcanzar el cociente de crédito de Morelos equivaldría a elevarlo a $2.78 \%$. Con esto, se estima: $[\ln (2.78)-\ln (1.15)] * 0.081 * 100=0.883 * 0.081 * 100=7.1$ puntos porcentuales.
} 
entidades federativas de México, particularmente las del sur. El efecto del crédito bancario sobre el crecimiento es, por tanto, estadística y económicamente significativo.

En relación con la variable Exportaciones, adoptada en este trabajo como medida de exposición al comercio internacional, se observa también una relación positiva y estadísticamente significativa, resultado congruente con la literatura que sugiere que una mayor apertura al comercio exterior estaría asociada con mayores niveles de crecimiento económico (Sachs and Werner, 1995; Frankel y Romer, 1999; Barro, 2001; Chang et al., 2009 y Messmacher, 2000). Con respecto al resto de variables de control, el rezago del logaritmo del PIB real per cápita, $y_{i, t-1}$, presenta una asociación positiva y estadísticamente significativa con la tasa de crecimiento del PIB real per cápita, sugiriendo que cuando el nivel de PIB per cápita ha experimentado un incremento en el periodo " $t$ - 1 ", el crecimiento del PIB per cápita es susceptible de crecer a un ritmo mayor en el periodo " $t$ ". Por otro lado, el coeficiente de Gasto Público es negativo y estadísticamente significativo, sugiriendo que este tiende a desplazar al gasto privado (efecto crowding out; véase Barro, 1991 y 2001; De Gregorio, 1992). El coeficiente estimado de la variable Capital Humano indica, conforme a lo esperado, que un mayor nivel educativo está relacionado positivamente al crecimiento económico, sugiriendo que la escolaridad permite al trabajador desarrollar sus capacidades laborales y facilitar su adaptación o adopción de nuevas tecnologías (Barro, 2001). La variable Inflación muestra un efecto negativo y estadísticamente significativo al 1\% sobre la tasa de crecimiento del PIB per cápita estatal, consistente con el argumento de que un ambiente de mayor estabilidad de precios, reflejado en menores tasas de inflación, al propiciar un ambiente de mayor estabilidad y certidumbre a los agentes económicos (empresas y familias), promueve la inversión y el gasto privado, y con ello, un mayor crecimiento económico (Barro, 2013; Schwartz y Pérez-López, 2000;). Finalmente, el coeficiente de Infraestructura registra un signo contrario al anticipado; no obstante, no resulta estadísticamente distinto de cero, quizá reflejando que la medida de infraestructura utilizada en las estimaciones podría no ser lo suficientemente amplia para capturar el efecto esperado. $^{25}$

\footnotetext{
${ }^{25}$ La literatura económica en torno a la relación entre crecimiento económico e infraestructura no es concluyente. Aschauer (1990) destaca, por ejemplo, un canal positivo de infraestructura al crecimiento
} 


\subsection{Pruebas de Robustez: Estimaciones Excluyendo la Ciudad de México}

Con el fin de investigar la robustez de las estimaciones, y considerando que la Ciudad de México reporta un nivel de crédito bancario a las empresas privadas no financieras de los sectores agropecuario, industrial y de servicios muy superior a la media nacional (Gráfica 2), lo que podría sesgar los resultados, el Cuadro 4 muestra las estimaciones que surgen de excluir las observaciones de dicha entidad federativa, considerando las mismas especificaciones del Cuadro $3 .{ }^{26}$ Los resultados muestran que en todas las especificaciones se corrobora la no presencia de auto-correlación serial de orden dos, tal como lo muestra la prueba de Arellano-Bond (2); no obstante, en las especificaciones (1) y (4) es posible rechazar la prueba de sobre-identificación de Hansen, por lo que son descartadas del análisis. De aquí que, comparando las especificaciones (2) y (3) del modelo con el Método Generalizado de Momentos en Diferencias, con sus contrapartes del modelo en Sistemas, (5) y (6), se observa que la variable CRÉDITO mantiene la asociación positiva y estadísticamente significativa con el crecimiento del PIB real per cápita. Cabe mencionar que si bien las estimaciones tienden a ser consistentes en lo referente al signo y significancia estadística del coeficiente de la variable CRÉDITO, su magnitud disminuye marginalmente, resultado que subraya la ya mencionada relevancia de la Ciudad de México en este indicador. ${ }^{27}$ De acuerdo con esta especificación, el coeficiente estimado de la variable CRÉDITO de 0.061, implica que un incremento de $10 \%$ en el financiamiento bancario a las empresas privadas no financieras como porcentaje del PIB, eleva la tasa de crecimiento económico per cápita estatal en 0.61 puntos porcentuales. ${ }^{28}$

económico; en cambio, Banerjee, Duflo y Qian (2020) analizan el caso de China y argumentan que el efecto de la infraestructura sobre el crecimiento del PIB per cápita podría ser nulo. Para el caso de México, Aschauer (1998) y Barajas y Gutiérrez (2012) reportan un efecto positivo de infraestructura sobre el crecimiento económico agregado.

${ }^{26} \mathrm{Si}$ se extrae a la Ciudad de México, el promedio del crédito bancario como porcentaje del PIB de las 31 entidades federativas restantes es $5.8 \%$.

${ }^{27}$ Vea Gráfica 2 y Gráfica 3.

${ }^{28}$ En este caso, los resultados de la columna (6) del Cuadro 4 implican que si el promedio del crédito bancario como porcentaje del PIB en la región sur para el año 2018 (4.06\%) alcanzara a su respectivo de la región centro $(8.06 \%)$, la tasa de crecimiento anual del PIB real per cápita en el sur aumentaría 4.1 puntos porcentuales $[=\ln (8.06)-\ln (4.06)]^{*} 0.061 * 100$. A su vez, el contrafactual de elevar el crédito bancario del estado de Guerrero en 2018 como porcentaje del PIB (1.15\%) al registrado ese mismo año en Morelos (2.78\%) resulta en un incremento en la tasa de crecimiento anual del PIB real per cápita de Guerrero en 5.4 puntos porcentuales $\left.[=\ln (2.78)-\ln (1.15)]^{*} 0.061 * 100\right]$. 


\section{Cuadro 4}

Crecimiento PIB per cápita y Crédito de la Banca Comercial, Estimación del Modelo Panel Dinámico Excluyendo Ciudad de México Variable Dependiente: Crecimiento del PIB real per cápita

\begin{tabular}{|c|c|c|c|c|c|c|}
\hline \multirow[b]{2}{*}{ Variables Explicativas: } & \multicolumn{3}{|c|}{ a) GMM en Diferencias } & \multicolumn{3}{|c|}{ b) GMM en Sistemas } \\
\hline & (1) & (2) & (3) & (4) & (5) & (6) \\
\hline CRÉDITO & $\begin{array}{l}-0.008 \\
(0.007)\end{array}$ & $\begin{array}{c}0.069 * * * \\
(0.021)\end{array}$ & $\begin{array}{l}0.040 * \\
(0.020)\end{array}$ & $\begin{array}{c}0.050 * * \\
(0.020)\end{array}$ & $\begin{array}{c}0.059 * \\
(0.030)\end{array}$ & $\begin{array}{c}0.061 * \\
(0.032)\end{array}$ \\
\hline$y_{t-1}$ & $\begin{array}{c}0.079 \\
(0.052)\end{array}$ & $\begin{array}{c}-0.192 \\
(0.124)\end{array}$ & $\begin{array}{c}-0.158 * \\
(0.095)\end{array}$ & $\begin{array}{c}-0.006 * * \\
(0.002)\end{array}$ & $\begin{array}{c}0.052 \\
(0.048)\end{array}$ & $\begin{array}{c}0.073 \\
(0.052)\end{array}$ \\
\hline Exportaciones & & $\begin{array}{c}0.059 \\
(0.038)\end{array}$ & $\begin{array}{c}0.064 * * \\
(0.029)\end{array}$ & & $\begin{array}{c}0.031 \\
(0.050)\end{array}$ & $\begin{array}{c}0.047^{*} \\
(0.025)\end{array}$ \\
\hline Inflación & & $\begin{array}{c}-0.142^{* * *} \\
(0.030)\end{array}$ & $\begin{array}{c}-0.069 * \\
(0.039)\end{array}$ & & $\begin{array}{c}-0.147^{* * *} \\
(0.031)\end{array}$ & $\begin{array}{c}-0.214^{* * *} \\
(0.063)\end{array}$ \\
\hline Gasto Público & & $\begin{array}{c}-0.074 * * * \\
(0.020)\end{array}$ & $\begin{array}{c}-0.055^{* * *} \\
(0.017)\end{array}$ & & $\begin{array}{c}-0.048 * * * \\
(0.016)\end{array}$ & $\begin{array}{c}-0.065^{* * *} \\
(0.012)\end{array}$ \\
\hline Infraestructura & & $\begin{array}{c}-0.477 * * * \\
(0.163)\end{array}$ & $\begin{array}{c}-0.425 * * * \\
(0.125)\end{array}$ & & $\begin{array}{c}0.001 \\
(0.060)\end{array}$ & $\begin{array}{l}-0.020 \\
(0.062)\end{array}$ \\
\hline Capital Humano & & $\begin{array}{c}0.028 \\
(0.036)\end{array}$ & $\begin{array}{c}0.019 \\
(0.027)\end{array}$ & & $\begin{array}{c}0.131 * * \\
(0.063)\end{array}$ & $\begin{array}{l}0.123 * * \\
(0.046)\end{array}$ \\
\hline Dummy de Crisis & & & $\begin{array}{c}-0.031 * * \\
(0.014)\end{array}$ & & & $\begin{array}{c}0.036 \\
(0.031)\end{array}$ \\
\hline Observaciones & 372 & 341 & 341 & 403 & 372 & 372 \\
\hline Entidades & 31 & 31 & 31 & 31 & 31 & 31 \\
\hline Número de Instrumentos & 7 & 17 & 17 & 7 & 17 & 14 \\
\hline Prueba AR(1) & 0.000 & 0.000 & 0.000 & 0.000 & 0.000 & 0.001 \\
\hline Prueba AR(2) & 0.965 & 0.707 & 0.119 & 0.241 & 0.215 & 0.694 \\
\hline Prueba de Hansen ( $p$-value) & 0.000 & 0.475 & 0.243 & 0.001 & 0.107 & 0.250 \\
\hline
\end{tabular}

Nota: Errores estándar robustos a heteroscedasticidad entre paréntesis. Dado que se usa la variante en Dos pasos, se utiliza la corrección de errores estándar para muestras finitas propuesta por Windmeijer (2005). Los símbolos $* * *, * *$ y $*$ denotan nivel de significancia del 1\%, 5\% y 10\%, respectivamente.

Fuente: Estimaciones propias con información del Banco de México e INEGI.

\subsection{Sucursales per cápita y Crecimiento Económico}

Un indicador alternativo de financiamiento bancario identificado en la literatura como posible determinante del crecimiento económico, es el número de sucursales bancarias per cápita, o el crecimiento de estas. Para propósitos de este trabajo, el argumento es que un número inadecuado de sucursales en una entidad federativa determinada pudiera restringir el acceso a los servicios bancarios y generar mayores costos de transacción a las empresas, limitando el número de proyectos potencialmente rentables que pudieran ser financiados, o 
bien, obligando a pequeños empresarios a recurrir a fuentes informales de crédito con mayores costos del mismo. Es de esperar, por tanto, que un menor número de sucursales bancarias per cápita, o tasas más bajas de crecimiento de este indicador, se traduzcan en menores tasas de crecimiento económico (Bardhan y Sharma, 2017). La Gráfica 4 muestra el número de sucursales bancarias por cada 100 mil habitantes por entidad federativa en México en 2018. En esta se pueden apreciar, nuevamente, diferencias para dicho indicador entre las diferentes entidades.

\section{Gráfica 4}

Número de Sucursales por cada 100 mil habitantes por Entidad Federativa, 2018

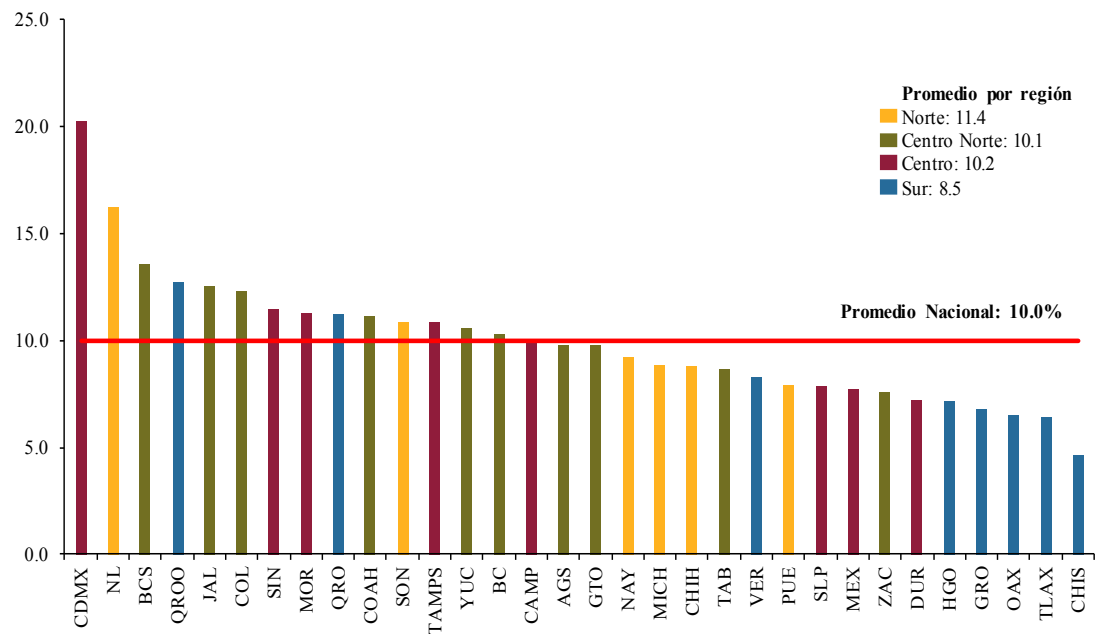

Fuente: Elaboración propia con información de la CNBV e INEGI.

La Gráfica 5 presenta, a su vez, lo que pudiera ser una asociación positiva entre el número de sucursales por cada 100 mil habitantes y el crecimiento económico para el periodo 20052018. Como se puede observar, el grado de asociación lineal entre este indicador y el crecimiento económico (medido por el coeficiente de correlación de Spearman) resulta estadísticamente significativo a un nivel de $10 \%$. 
Gráfica 5

Crecimiento Económico y Sucursales Bancarias por cada 100 mil habitantes

Promedio 2005-2018 por Entidad Federativa

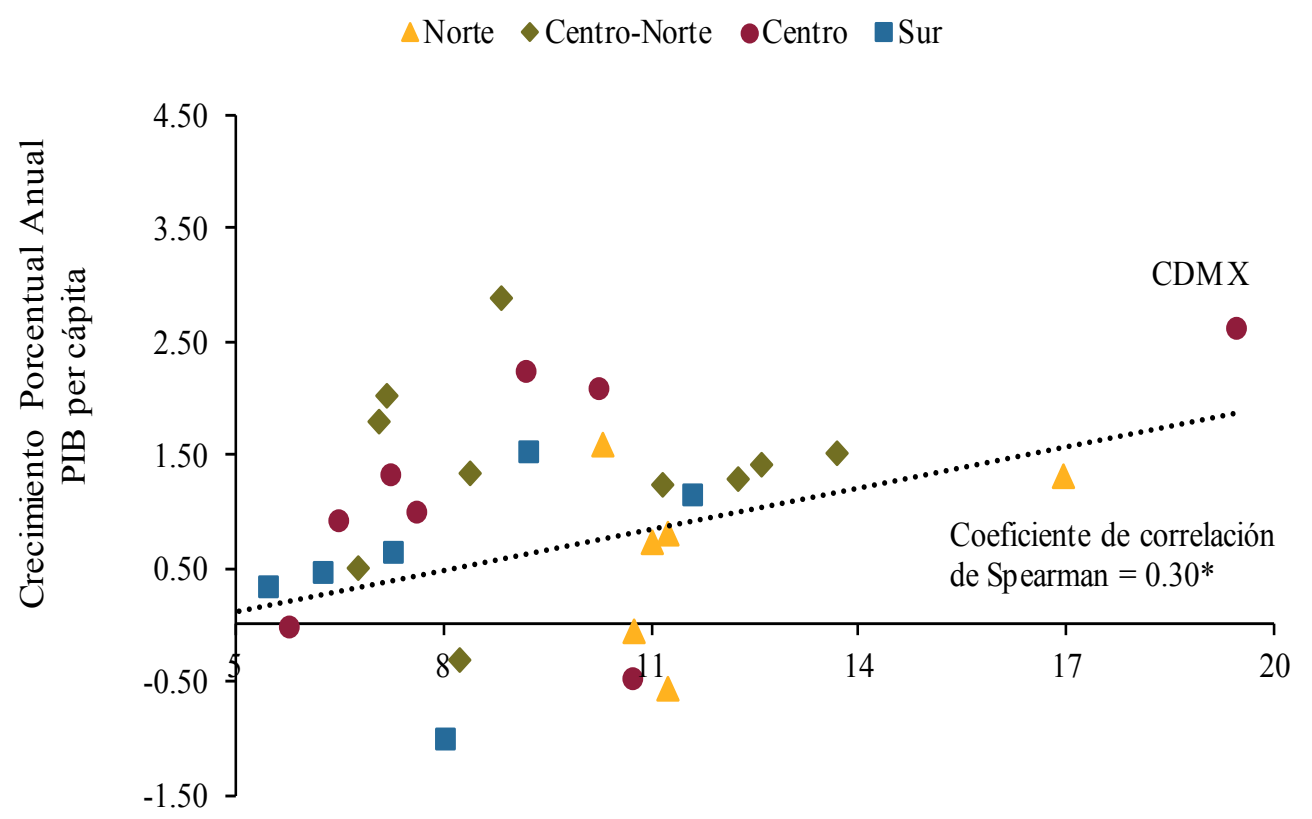

Sucursales por cada 100 mil habitantes

Nota: * denota significancia estadística al 10\%. Si se excluye a la Ciudad de México, el coeficiente de correlación de Spearman baja a 0.22 y resulta estadísticamente no significativo al $10 \%$. Los puntos corresponden al valor promedio de las variables por entidad federativa durante el periodo 2005-2018; el color representa la región.

Fuente: Elaboración propia con base en información del INEGI y CNBV.

Considerando lo anterior, el Cuadro 5 presenta los resultados de un ejercicio econométrico similar al realizado en los Cuadros 3 y 4 , utilizando como alternativas del crédito bancario a las empresas privadas no bancarias como porcentaje del PIB, al número de sucursales bancarias por cada 100 mil habitantes por entidad federativa y al crecimiento de este último. ${ }^{29}$ El panel a) del Cuadro 5 presenta los resultados de las estimaciones utilizando el Método Generalizado de Momentos en Diferencias, en tanto que el panel b) lo hace para el modelo en Sistemas. Las especificaciones (1)-(2), y (5)-(6) incluyen el total de observaciones, mientras que las especificaciones (3)-(4) y (7)-(8) excluyen la Ciudad de México.

\footnotetext{
${ }^{29} \mathrm{El}$ Apéndice 4 muestra las respectivas pruebas de causalidad de Granger en panel de datos para las variables "Sucursales por cada 100 mil habitantes" y "Crecimiento de las sucursales por cada 100 mil habitantes", con el crecimiento del PIB real per cápita. Los resultados, para ambas, sugieren una causalidad bidireccional con el crecimiento del PIB per cápita, lo que a su vez refiere el trato endógeno de las mismas en los modelos en diferencias y en sistemas estimados en el Cuadro 4.
} 


\section{Cuadro 5}

Crecimiento PIB per cápita vs. Sucursales Bancarias per cápita, por Entidad Federativa Estimación del Modelo Panel Dinámico (GMM) Variable Dependiente: Crecimiento del PIB real per cápita

\begin{tabular}{|c|c|c|c|c|c|c|c|c|}
\hline \multirow[b]{2}{*}{ Variables Explicativas: } & \multicolumn{4}{|c|}{ a. GMM en Diferencias } & \multicolumn{4}{|c|}{ b. GMM en Sistemas } \\
\hline & (1) & (2) & (3) & (4) & (5) & (6) & (7) & (8) \\
\hline \multirow{2}{*}{ No. Sucursales per cápita } & $-0.059 *$ & & -0.046 & & -0.004 & & 0.001 & \\
\hline & $(0.034)$ & & $(0.042)$ & & $(0.061)$ & & (0.046) & \\
\hline \multirow[t]{2}{*}{ Crec. Sucursales per cápita } & & $0.232 * * *$ & & $0.303^{* * *}$ & & $0.157^{*}$ & & $0.189 * *$ \\
\hline & & $(0.050)$ & & $(0.076)$ & & $(0.086)$ & & $(0.070)$ \\
\hline \multirow[t]{2}{*}{$y_{t-1}$} & -0.085 & $-0.153^{*}$ & -0.092 & $-0.241 * *$ & $0.052^{* *}$ & 0.013 & 0.029 & -0.010 \\
\hline & $(0.060)$ & $(0.080)$ & $(0.072)$ & (0.094) & $(0.025)$ & $(0.022)$ & $(0.041)$ & $(0.018)$ \\
\hline \multirow[t]{2}{*}{ Exportaciones } & $0.066^{* * *}$ & $0.044 * *$ & $0.078 * * *$ & 0.008 & $0.048 * * *$ & 0.003 & $0.043 * * *$ & -0.008 \\
\hline & $(0.017)$ & $(0.020)$ & $(0.019)$ & $(0.032)$ & $(0.017)$ & $(0.030)$ & $(0.012)$ & (0.018) \\
\hline \multirow[t]{2}{*}{ Inflación } & -0.005 & -0.010 & -0.003 & $-0.017^{*}$ & -0.010 & 0.019 & -0.015 & $0.023^{* *}$ \\
\hline & $(0.008)$ & $(0.008)$ & $(0.009)$ & $(0.009)$ & $(0.026)$ & (0.017) & $(0.022)$ & $(0.010)$ \\
\hline \multirow[t]{2}{*}{ Gasto Público } & $-0.018 * *$ & $-0.014^{*}$ & $-0.030 * * *$ & -0.012 & $-0.010^{*}$ & 0.000 & $-0.016^{* * *}$ & -0.002 \\
\hline & $(0.008)$ & $(0.008)$ & $(0.010)$ & $(0.012)$ & $(0.005)$ & $(0.009)$ & $(0.005)$ & $(0.005)$ \\
\hline \multirow[t]{2}{*}{ Infraestructura } & $-0.133 * *$ & -0.069 & $-0.190 *$ & 0.144 & -0.028 & 0.008 & 0.004 & $0.037^{* *}$ \\
\hline & $(0.061)$ & $(0.102)$ & $(0.114)$ & $(0.163)$ & $(0.024)$ & (0.025) & $(0.045)$ & $(0.016)$ \\
\hline \multirow[t]{2}{*}{ Capital Humano } & 0.023 & -0.015 & 0.020 & -0.020 & $0.115^{* * *}$ & $0.069^{*}$ & $0.115^{* * *}$ & $0.057^{*}$ \\
\hline & $(0.017)$ & $(0.023)$ & $(0.018)$ & $(0.023)$ & $(0.026)$ & $(0.036)$ & $(0.025)$ & $(0.032)$ \\
\hline \multirow[t]{2}{*}{ Dummy de Crisis } & $-0.048 * * *$ & $-0.049 * * *$ & $-0.049 * * *$ & $-0.043 * * *$ & $-0.072 * * *$ & $-0.092 * * *$ & $-0.070 * * *$ & $-0.097 * * *$ \\
\hline & $(0.006)$ & $(0.007)$ & $(0.007)$ & $(0.008)$ & (0.014) & $(0.015)$ & $(0.013)$ & $(0.012)$ \\
\hline Observaciones & 352 & 352 & 341 & 341 & 384 & 384 & 372 & 372 \\
\hline Entidades & 32 & 32 & 31 & 31 & 32 & 32 & 31 & 31 \\
\hline Número de Instrumentos & 17 & 17 & 17 & 17 & 17 & 17 & 17 & 17 \\
\hline Prueba AR(1) & 0.000 & 0.000 & 0.000 & 0.000 & 0.000 & 0.000 & 0.000 & 0.000 \\
\hline Prueba AR(2) & 0.0189 & 0.919 & 0.0474 & 0.971 & 0.0927 & 0.697 & 0.0841 & 0.305 \\
\hline Prueba de Hansen ( $p$-value) & 0.00717 & 0.00508 & 0.0261 & 0.00965 & 0.140 & 0.0873 & 0.409 & 0.683 \\
\hline
\end{tabular}

Nota: Errores estándar robustos a heteroscedasticidad entre paréntesis. GMM hace referencia a "Método Generalizado de Momentos." Dado que se usa la variante en Dos Pasos, se utiliza la corrección de errores estándar para muestras finitas propuesta por Windmeijer (2005). Los símbolos ***,** y * denotan nivel de significancia del $1 \%, 5 \%$ y $10 \%$, respectivamente.

Fuente: Estimaciones propias con información del Banco de México e INEGI.

Tal como se observa, es la especificación de la columna 8, misma que considera el crecimiento de las sucursales por cada 100 mil habitantes y excluye la Ciudad de México, donde se rechaza la prueba de Arellano-Bond y de sobre-identificación de Hansen, por lo cual es la preferida. En esta especificación, el coeficiente del número de sucursales por cada 100 mil habitantes resultó estadísticamente distinto de cero a un nivel de significancia del 5\%. Asimismo, los coeficientes de las variables Infraestructura, Capital Humano y Crisis resultaron estadísticamente distintos de cero y con el signo esperado, en tanto que el coeficiente de Inflación resultó estadísticamente distinto de cero, aunque sin el signo esperado. Por su parte, los coeficientes estimados de crecimiento en el número de sucursales por cada 100 mil habitantes por entidad federativa resultaron positivos y estadísticamente significativos, indicando que un incremento de $1 \%$ en la tasa de crecimiento del número de 
sucursales se traduce en un aumento de $0.19 \%$ en la tasa de crecimiento del PIB per cápita. Estos resultados advierten sobre la posibilidad de que el crecimiento en el número de sucursales pudiera estar asociado con una mayor disponibilidad de intermediarios financieros facilitadores tanto de captación como movilización de recursos financieros, lo que a su vez podría asociarse con efectos positivos en el crecimiento económico. ${ }^{30}$

\subsection{Algunas Limitantes}

Debe reconocerse, no obstante, que los resultados obtenidos aquí enfrentan diversas limitantes. Por ejemplo, si bien se consideró en el análisis la información relevante disponible a nivel de entidad federativa, probablemente exista una lista de variables omitidas para las cuales el crédito bancario sería solo una proxy; esto es, que el coeficiente del crédito pudiera estar capturando el efecto de otras variables, por ejemplo, el de aquellas relacionadas con avances tecnológicos (Paxson, 1996).

Otro problema es que el periodo analizado pudiera ser considerado no lo suficientemente largo para un estudio de crecimiento económico. Adicionalmente, sería de interés contar con datos sobre crédito bancario al sector privado no financiero por entidad federativa desagregados por sector (agropecuario, industrial y de servicios) a fin de determinar si el crédito bancario a los diferentes sectores tiene efectos diferenciados sobre el crecimiento económico estatal. De igual manera, sería deseable contar con información a nivel de entidad federativa del crédito bancario a la vivienda y al consumo, para determinar sus efectos individuales sobre el crecimiento. Esto obliga a que en caso de que emerja nueva información relevante sobre determinantes potenciales del crecimiento económico estatal, se revisen las estimaciones aquí presentadas.

\section{Consideraciones Finales}

Existe abundante literatura que documenta que el crédito bancario al sector privado ejerce un efecto positivo sobre el crecimiento económico. Bajo esta premisa, y tomando en cuenta la tendencia ascendente del crédito bancario a las empresas privadas no financieras de los sectores agropecuario, industrial y de servicios observada en México en las últimas dos décadas, este trabajo investiga si dicho crédito pudiera estar impulsando el crecimiento

\footnotetext{
${ }^{30}$ Vea Jayaratne y Strahan (1996).
} 
económico del país. Para este objetivo se construyó un panel de datos anuales por entidad federativa para el periodo 2005-2018 y, siguiendo a Levine et al. (2000), se llevaron a cabo estimaciones empleando el Método Generalizado de Momentos en Diferencias y en Sistemas.

Los resultados sugieren que, una vez que se controla por un grupo de variables exógenas comúnmente empleadas en regresiones de crecimiento económico, el crédito bancario a las empresas privadas no financieras ejerce un efecto positivo, estadística y económicamente significativo, sobre el crecimiento del PIB per cápita en las entidades federativas del país en el periodo señalado. En particular, las especificaciones econométricas preferidas sugieren que, todo lo demás constante, un incremento de $10 \%$ en el crédito bancario al sector privado no financiero como porcentaje del PIB incrementa el crecimiento económico estatal en 0.81 puntos porcentuales cuando se incluyen las 32 entidades federativas, y de 0.61 puntos porcentuales cuando se excluye a la Ciudad de México. Estos efectos son mayores a los reportados en la literatura, si bien debe tomarse en cuenta que existe una variedad de factores que pudieran explicar dichas diferencias o que evitan una comparación directa. Los resultados confirman que, en años recientes, el crédito bancario al sector privado no financiero ha jugado un papel positivo en el crecimiento económico de México. 


\section{Referencias}

Abrigo, M. e I. Love (2016), "Estimation of Panel Vector Autoregression in Stata." The Stata Journal, Vol. 16, No. 3, pp. 778-804.

Aizenman, J., Jinjarak, Y. y D. Park (2015), "Financial Development and Output Growth in Developing Asia and Latin America: A Comparative Sectoral Analysis.” NBER Working Paper No. 20917, NBER. Cambridge, Mass.

Alonso-Borrego, C. y M. Arellano (1999), "Symetrically Normalized Instrumental-Variable Estimation Using Panel Data," Journal of Business and Economic Statistics, Vol. 17, No. 1, pp. 36-49.

Arellano, M. y O. Bover (1995), "Another Look at the Instrumental Variable Estimation of Error-Components Models.” Journal of Econometrics, Vol. 68, No. 1, pp. 29-51.

Arellano, M. y S. Bond (1991), "Some Tests of Specification for Panel Data: Monte Carlo Evidence and an Application to Employment Equations." The Review of Economic Studies, Vol. 58, No. 2, pp. 227-297.

Arestis, P. y P. Demetriades (1999), "Finance and Growth: Institutional Considerations, Financial Policies and Causalities." Zagreb International Review of Economics and Business, Vol. 2, No. 1, pp. 37-62.

Arestis, P., Demetriades, P., Fattouh, B. y C. Mouratidis (2002), "The Impact of Liberalization Policies on Financial Development: Evidence from Developing Countries." International Journal of Finance and Economics, Vol. 7, No. 2, pp. 109-121.

Aschauer, D. (1998), "The Role of Public Infrastructure Capital in Mexican Economic Growth.” Economía Mexicana, Nueva Época, Vol. 7, No. 1, pp. 47-78

Aschauer, D. (1990), "Why is Infrastructure Important?" Proceedings of a Conference. Federal Reserve Bank of Boston.

Baltagi, B. (2013), Econometric Analysis of Panel Data. $5^{\text {th }}$ Edition. John Wiley \& Sons Ltd.: England.

Banco de México (2020). Reporte Sobre las Economías Regionales, Enero-Marzo, p. 1.

Banerjee, A., Duflo, E. y N. Qian (2020), "On the Road: Access to Transportation Infrastructure and Economic Growth in China." Journal of Development Economics, No. 45, pp. $1-36$. 
Barajas, A., Chami, R. y S. Reza (2013), “The Finance and Growth Nexus Re-examined: Do All Countries Benefit Equally?" IMF Working Paper 13/130. International Monetary Fund, Washington, D.C.

Barajas, H. y L. Gutiérrez (2012), "La Importancia de la Infraestructura Física en el Crecimiento Económico de los Municipios de la Frontera Norte." Estudios Fronterizos, Vol. 13, No. 25, pp. 57-88.

Bardhan, S. y R. Sharma (2017), "Does Regional Financial Matter for Growth? Evidence from Indian States.” International Economic Journal, Vol. 31, No. 4, pp. 621-646.

Barro, R. (1991), "A Cross-country Study of Growth, Saving and Government." En D. Bernheim y J. Shoven (eds.): National Saving and Economic Performance, NBER, University of Chicago Press, Chicago, Illinois, pp. 271-301.

Barro, R. (2001), "Human Capital and Economic Growth," American Economic Review, Vol. 91, No. 2, pp. 12-17.

Barro, R. (2013), "Inflation and Economic Growth." Annals of Economics and Finance, Vol. 14, No. 1, pp. 85-109.

Beck, T. y R. Levine (2004), "Stock Markets, Banks, and Growth: Panel Evidence”, Journal of Banking \& Finance, Vol. 28, No. 3, pp. 423-442.

Beck, T., Levine, R. y N. Loayza (2000), "Finance and the Sources of Growth.” Journal of Financial Economics, Vol. 58, No. 1-2, pp. 261-300.

Beck, T., H. Degryse y C. Kneer (2014), "Is More Finance Better? Disentangling Intermediation and Size Effects of Financial Systems." Journal of Financial Stability, Vol. 10-C, pp. 50-64.

Beck, T., Demirguc-Kunt, A., Laeven, L. y R. Levine (2008), "Finance, Firm Size and Growth." Journal of Money, Credit and Banking, Vol. 40, No. 7, pp. 1379-1405.

Blundell, R. y S. Bond (1998), "Las Condiciones Iniciales y las Restricciones de Momentos en los Métodos de Datos Panel Dinámicos." Journal of Econometrics, Vol. 87, No. 1, pp. 115-143.

Bucci, A. y S. Marsiglio (2019), "Financial Development and Economic Growth: Long Run Equilibrium and Transitional Dynamics." Scottish Journal of Political Economy, Vol. 66, No. 3, pp. 331-359.

Chang, R., Kaltani, L. y Loayza, N. (2009), “Openness can be Good for Growth: The Role of Policy Complementarities.” Journal of Development Economics, Vol. 90, No. 1, 33-49. 
Choi, I. (2001), "Unit Root for Panel Data." Journal of International Money and Finance, Vol. 20, No. 2, pp. 249-272.

Davidson, R. y MacKinnon, J. (2004), Econometric Theory and Methods. Oxford University Press: New York.

De Gregorio, J. (1992), "Economic Growth in Latin America." Journal of Development Economics, Vol. 39, No. 1, pp. 59-84.

De Gregorio, J. y P. E. Guidotti (1995), "Financial Development and Economic Growth." World Development, Vol. 23, No. 3, pp.433-448.

De la Cruz, J. y J. Alcántara (2011), "Crecimiento Económico y el Crédito Bancario: Un Análisis de Causalidad para México." Revista de Economía, Vol. 28, No.7, pp. 13-38.

Deidda, L. y B. Fattouh (2002), "Non-linearity between Finance and Growth," Economics Letters, Vol. 74, No. 3, pp. 339-345.

Demetriades, P. y K. Hussein (1996), "Does Financial Development Cause Economic Growth? Time-Series Evidence from 16 Countries." Journal of Development Economics, Vol. 51, No. 2, pp. 387-411.

Demirgüç-Kunt, A. y V. Maksimovic (1995), "Stock Market Development and Firm Financing Choices." The World Bank Economic Review, Vol. 10, No. 2, pp. 341-369.

Fama, E. (1980), "Banking in the Theory of Finance." Journal of Monetary Economics, Vol. 6, No. 1, pp. 39-57.

Frankel, J. y D. Romer (1999), “Does Trade Cause Growth?” American Economic Review, Vol. 89, No. 3, pp. 379-99.

Giovannini, A., Iacopetta, M. y R. Minetti (2013), "Financial Markets, Banks, and Growth: Disentangling the Links." Revue de l'ORCE/Débats et Politiques. No. 131.

Guiso, L., Jappelli, T., Padula, M. y M. Pagano (2004), "Financial Market Integration and Economic Growth in the EU." Economic Policy, Vol. 19, No. 40, pp. 523-577.

Hassan, I. y L. Klapper (2006), "Firms' Access to Finance: Entry, Growth, and Productivity." In Finance for All? Policies and Pitfalls in Expanding Access, World Bank Policy Report, Ch. 2.

Hassan M., Sánchez, B. y J. Yu (2011), "Financial Development and Economic Growth: New Evidence from Panel Data." The Quarterly Review of Economics and Finance, Vol. 51, No. 1, pp. 88-104. 
Herman, A. y A. Klemm (2017), "Financial Deepening in Mexico.” IMF Working Paper WP/17/19. International Monetary Fund, Washington, D.C.

Hernández, F. y A. Villagómez (2013), El Enigmático Sistema Bancario Mexicano Contemporáneo. Primera Edición. CEEY Editorial.

Holtz-Eakin, D., Newey, W. y H. Rosen, (1988), "Estimating Vector Autoregressions with Panel Data.” Econometrica, No. 56, Vol. 6, pp. 1371-1395.

Im, K., Pesaran, H. y Y. Shin (2003), “Testing for Unit Roots in Heterogeneous Panels.” Journal of Econometrics, Vol. 115, No. 1, pp. 53-74.

Jayaratne, J. y P. Strahan (1996), "The Finance-Growth Nexus: Evidence from Bank Branch Deregulation.” The Quarterly Journal of Economics. Vol. 111, No. 3, pp. 639-670.

Kendall, J. (2009), "Local Financial Development and Growth.” The World Bank. Policy Research Working Paper No. 4838.

King, R. y R. Levine (1993), “Finance and Growth: Schumpeter Might Be Right?” Quarterly Journal of Economics, Vol. 108, No. 3, pp. 717-737.

Law, S. y N. Singh (2014), "Does Too Much Finance Harm Economic Growth.” Journal of Banking \& Finance, Vol. 41, pp. 36-44.

Levin, A., Lin, C. y J. Chu (2002). "Testing for Unit Roots in Panel Data: Asymptotic and Finite-sample Properties." Journal of Econometrics, Vol. 108, No. 1, pp. 1-24.

Levine, R. (1997), "Financial Development and Economic Growth: Views and Agenda." Journal of Economic Literature, Vol. 35, No. 2, pp. 688-726.

Levine, R. (2005), "Finance and Growth: Theory and Evidence." Handbook of Economic Growth. Philippe Aghion and Steven Durlauf (Eds), Elsevier B.V., Vol. 1, Part A, pp. 865-934.

Levine, R., Loayza, N., y T. Beck (2000), "Financial Intermediation and Growth: Causality and Causes." Journal of Monetary Economics, Vol. 46, No. 1, pp. 31-77.

Levine, R. y S. Zervos (1998), "Stock Markets, Banks, and Economic Growth." American Economic Review, Vol. 88, No. 3, pp. 537-58.

Messmacher, M. (2000), "Desigualdad Regional en México. El Efecto del TLCAN y Otras Reformas Estructurales.” Documento de Investigación del Banco de México No. 2000-4. Diciembre. 
Musso, P. y S. Schiavo (2008), "The Impact of Financial Constraints on Firm Survival and Growth.” Journal of Evolutionary Economics, Vol. 18, No. 2, pp. 135-149.

Nava, A. y P. Dorantes (2016), "La Reciente Reforma Financiera en México: Transformaciones y Perspectivas.” Economía UNAM, Vol. 13, No. 37, pp. 89-106.

Nickell, S. (1981), "Biases in Dynamic Models with Fixed Effects.” Econometrica, Vol. 49, No. 6, pp. 1417-1426.

Nili, M. y M. Rastad (2007), "Addressing the Growth Failure of the Oil Economies: The Role of Financial Development." Quarterly Journal of Economics. Vol. 127, No. 4, pp. 1551-69.

Nucci, F. y A. Pozzolo (2010), "The Exchange Rate, Employment, and Hours: What Firm Level Data Say.” Journal of International Economics, Vol. 82, No. 2, pp. 112-123.

Pasali, S. (2013), "Where is the Cheese? Synthesizing a Giant Literature on Causes and Consequences of Financial Sector Development." The World Bank Policy Research Working Paper No. 6655. October.

Paxson, C. (1996), "Saving and Growth: Evidence from Micro-Data." European Economic Review, Vol. 40, No. 2, pp. 255-288.

Rajan, R. y L. Zingales (1998), "Financial Dependence and Growth.” American Economic Review, Vol. 88, No. 3, pp. 559-86.

Roodman, D. (2009), "A Note on the Theme of Too Many Instruments." Oxford Bulletin of Economics and Statistics, Vol. 71, No. 1, pp. 135-158.

Rousseau, P. y P. Wachtel (2011), "What is Happening to the Impact of Financial Deepening on Economic Growth.” Economic Inquiry, Vol. 49, No. 1, pp. 276-88.

Porras, A. y G. Rosales (2014), “Crecimiento Económico, Banca y Desarrollo Financiero: Evidencia Internacional.” Estudios Económicos, Vol. 29, No. 2, pp. 263-300.

Sachs, J. y A. Werner (1995), "Natural Resource Abundance and Economic Growth.” NBER Working Paper No. 5398, NBER. Cambridge, Mass.

Sahay, R., Čihák, M., N’Diaye, P., Barajas, A., Bi, R., Ayala, D., Gao, Y., Kyobe, A., Nguyen, L., Saborowski, C., Svirydzenka, K. y S. Reza (2015), "Rethinking Financial Deepening: Stability and Growth in Emerging Markets." IMF Staff Discussion Note 15/08. May.

Schwartz, M. y A. Pérez-López. "Crecimiento Económico e Inflación: El Caso de México.” Economía Mexicana. Nueva Época, Vol. IX, No.2, pp. 165-188. 
Serres, A., Kobayakawa, S., Sløk, T. y L. Vartia (2006), "Regulation of Financial Systems and Economic Growth in OECD Countries: An Empirical Analysis." OECD Economic Studies, Vol. 43, No. 2, pp. 77-113.

Rioja, F. y N. Valev (2004), "Does One Size Fit All? A Reexamination of the Finance and Growth Relationship." Journal of Development Economics, Vol. 74, No. 2, pp. 429-447.

Rodríguez, D. y F. López (2009), "Desarrollo Financiero y Crecimiento Económico en México." Problemas del Desarrollo, Vol. 40, No. 159, pp. 39-60.

Turrent, E. (2007), "Las Tres Etapas de la Autonomía del Banco Central en México." Documento de Investigación del Banco de México No. 2007-10. Julio.

World Economic Forum (2012), The Financial Development Report 2012. World Economic Forum, New York: USA Inc.

Xu, Z. (2000), "Financial Development, Investment, and Growth." Economic Inquiry, Vol. 38, No. 2, pp. 331-344.

Venegas, F., Tinoco, M. y V. Torres (2009), "Desregulación Financiera, Desarrollo del Sistema Financiero y Crecimiento Económico en México: Efectos de Largo Plazo y Causalidad." Estudios Económicos, Vol. 24, No. 1, pp. 249-283.

Venegas, F., Tinoco, M. y V. Torres (2014), "Growth, Bank Credit, and Inflation in Mexico: Evidence from an ARDL-Bounds Testing Approach." Latin American Economic Review, Vol. 23, No. 8, pp. 1-22.

Windmeijer, F. (2005), "A Finite Sample Correction for the Variance of Linear Efficient Two-Step GMM Estimators.” Journal of Econometrics, Vol. 126, No. 1, pp. 25-51. 


\section{Apéndice 1}

Estadísticas Descriptivas 2005-2018

\begin{tabular}{lcccccc}
\hline Variable & No. Observaciones & Media & Desv. Estándar & Min. & Max & $\begin{array}{c}\text { Fuente de } \\
\text { Información }\end{array}$ \\
\hline PIB per cápita & 448 & 11.74 & 0.53 & 10.82 & 14.13 & INEGI \\
CRÉDITO & 448 & 1.26 & 0.88 & -1.97 & 4.13 & Banco de México \\
Infraestructura & 448 & 9.06 & 1.03 & 4.48 & 10.44 & INEGI \\
Gasto Público & 448 & 2.39 & 0.76 & 0.62 & 5.22 & INEGI \\
Exportaciones & 384 & 2.60 & 1.46 & -3.69 & 3.72 & INEGI \\
Inflación & 416 & 4.13 & 1.11 & 0.87 & 7.26 & INEGI \\
Capital Humano & 416 & 3.58 & 0.28 & 2.67 & 4.27 & INEGI \\
Sucursales por cada 100 mil habitantes & 448 & 2.20 & 0.34 & 1.27 & 3.07 & CNBV \\
\hline
\end{tabular}

Nota: Con excepción de la variable inflación, el resto son expresadas en logaritmos.

Fuente: Estimaciones propias con base en información del Banco de México e INEGI.

\section{Apéndice 2}

\section{Crédito de la Banca Comercial a Empresas Privadas No Financieras 2005-2018 Valores Anuales como \% PIB}

Eje Y: Crédito Bancario al Sector Privado No Financiero Total

Eje X: Crédito Bancario a los Sectores Agropecuario, industrial y de servicios

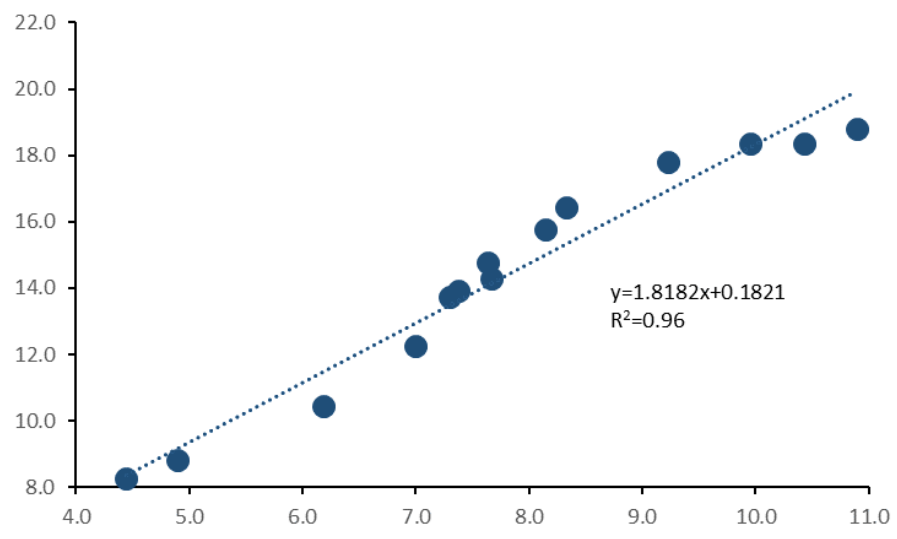

Fuente: Estimaciones propias con base en información del Banco de México e INEGI. 


\section{Apéndice 3}

\section{Pruebas de Causalidad de Granger con Datos Panel}

\section{Crecimiento del PIB real per cápita, Sucursales por cada 100 mil hab. y Crecimiento Sucursales por cada $100 \mathrm{mil} \mathrm{hab.}$}

\begin{tabular}{|c|c|c|c|c|c|}
\hline \multicolumn{3}{|c|}{ Relación Casusal } & \multirow{2}{*}{$\frac{\text { Rezago }}{1}$} & \multirow{2}{*}{$\frac{\chi^{2}}{0.533}$} & \multirow{2}{*}{$\frac{p \text {-value }}{0.465}$} \\
\hline Crec. PIB per cápita & $\not$ & Sucursales por cada 100 mil hab. & & & \\
\hline Sucursales por cada $100 \mathrm{mil}$ hab. & $\not$ & Crec. PIB per cápita & 1 & 2.919 & $0.088^{*}$ \\
\hline Crec. PIB per cápita & $\not$ & Sucursales por cada 100 mil hab. & 2 & 28.162 & $0.000 * * *$ \\
\hline Sucursales por cada 100 mil hab. & $\not$ & Crec. PIB per cápita & 2 & 4.634 & $0.099 *$ \\
\hline Crec. PIB per cápita & $\not$ & Crec. Sucursales por cada 100 mil hab & 1 & 29.18 & $0.033^{* *}$ \\
\hline Crec. Sucursales por cada 100 mil hab. & $\not$ & Crec. PIB per cápita & 1 & 5.28 & $0.002 * * *$ \\
\hline Crec. PIB per cápita & $\not$ & Crec. Sucursales por cada 100 mil hab & 2 & 30.794 & $0.000 * * *$ \\
\hline Crec. Sucursales por cada 100 mil hab. & $\not$ & Crec. PIB per cápita & 2 & 3.136 & 0.208 \\
\hline
\end{tabular}

Nota: El símbolo $\nRightarrow$ denota "no causalidad.” Los símbolos $* * *, * *$ y * denotan nivel de significancia del $1 \%$, $5 \%$ y $10 \%$, respectivamente.

Fuente: Estimaciones propias con base en información de la Comisión Nacional Bancaria y de Valores (CNBV) e INEGI. 